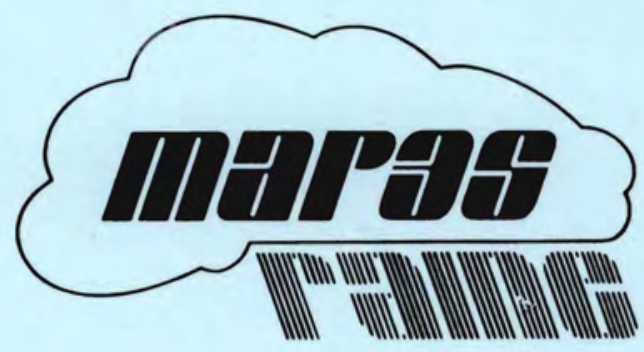

\title{
The MAP3S/RAINE
}

Precipitation Chemistry Network: Quality Control 
This report was prepared as an account of work sponsored by the United States Government. Neither the United States nor the Department of Energy, nor any of their employees. nor any of their contractors, subcontractors, or their emplovees, makes any warranty, express or implied, or assumes any legal liability or responsibility for the accuracy, completeness or usefulness of any information, apparatus, product or process disclosed, or represents that its use would not iniringe privately owned rights.

The views, opinions and conciusions contained in this report are those of the contractor and do not necessarily represent those of the United States Government or the United States Department of Energy.

\author{
PACIFIC NORTHWEST LABORATORY \\ operated by \\ BATTELLE \\ for the \\ UNITED STATES DEPARTMENT OF ENERGY \\ Under Contract DE-AC06-76RLO 1830
}

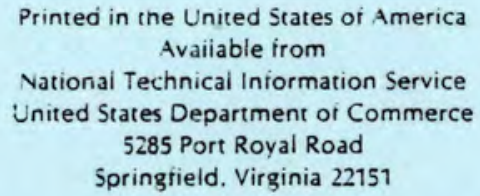

Price: Printed Copy $\mathbf{5}$ $\because$ Microfiche $\$ 3.00$

VIIS

*Pages Selling Price

001-025 $\quad \$ 4.00$

026-050 $\quad \$ 4.50$

051-075 $\$ 5.25$

076-100 $\quad \$ 6.00$

101-12S $\$ 6.50$

$125-150 \quad 57.25$

$151-175 \quad \$ 8.00$

$176-200 \quad \$ 9.00$

201-225 $\quad 59.25$

226-250 $\$ 9.50$

251-275 $\quad \$ 10.75$

$275-300 \quad \$ 11.00$ 


\section{6}

\section{THE MAP3S/RAINE PRECIPITATION CHEMISTRY NETWORK: \\ QUALITY CONTROL}

OCTOBER 1980

Prepared for the U.S. Environmental Protection Agency through U.S. Department of Energy Contract No. DE-AC06-76RLO 1830

Pacific Northwest Laboratory Richland, Washington 99352 
. 


\section{ABSTRACT}

The participants of the precipitation chemistry network of the MultiState Atmospheric Power Production Pollution Study/Regional Acidity of Industrial Emissions (MAP3S/RAINE) have developed procedures for maintenance of high quality output from the network operation. The documented proceduresmost of which were in place before the network began sampling in 1976-include those for site selection and verification, field equipment, laboratory and data handling, and external laboratory quality testing. 

CONTENTS

PAGE

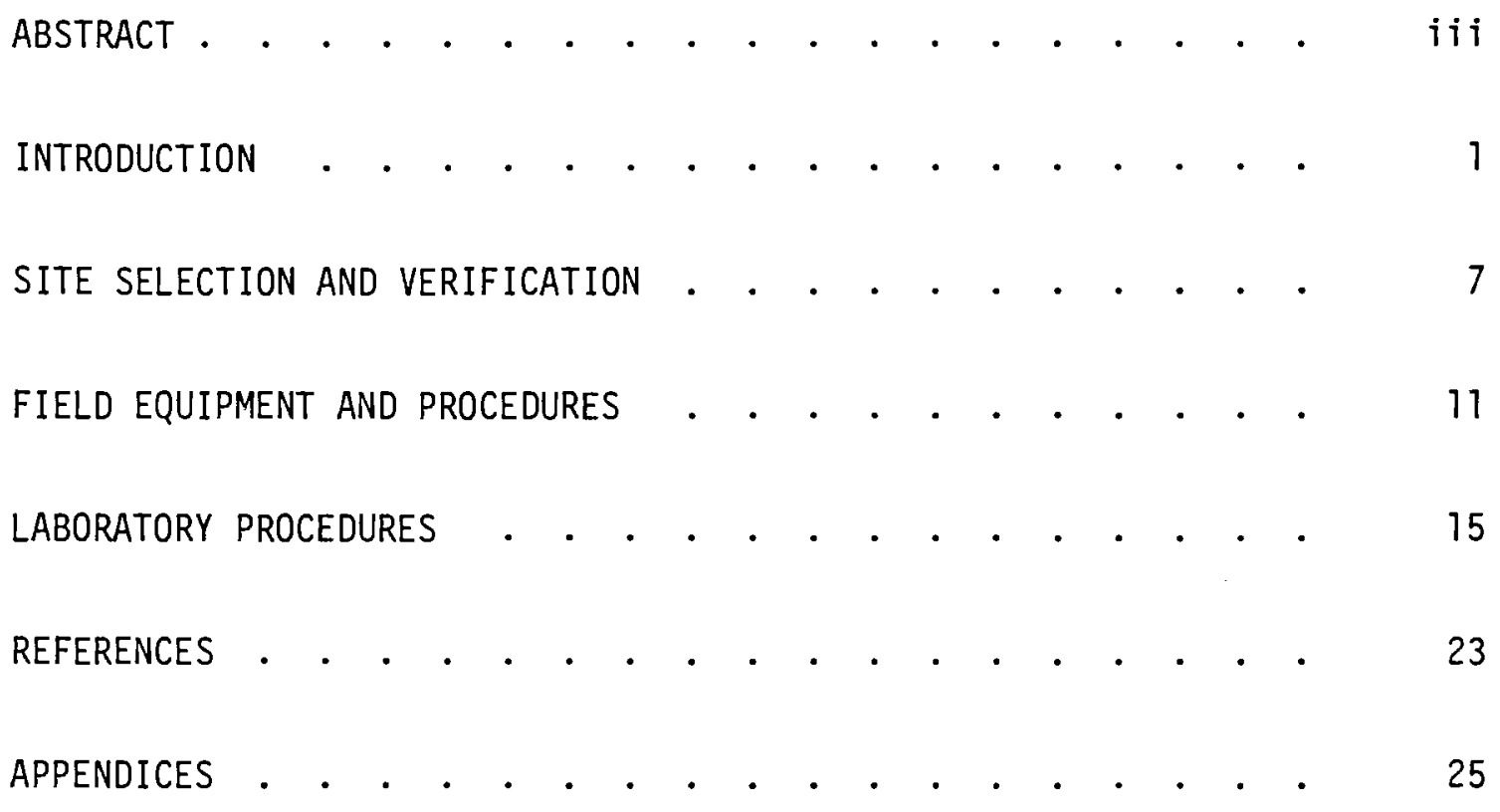


. 


\section{INTRODUCT ION}

The MAP3S Precipitation Chemistry Network was established in 1976 as an important component of the Multi-State Atmospheric Power Production Pollution Study, whose overall objective was the development of models to simulate and predict the effects of increased power production by fossil-fuel means in the eastern United States. The Network, through precipitation event sampling, has provided a much needed base of precipitation chemistry data; these data are useful for development and verification of the long range transport and deposition models which form the major portion of the MAP3S effort. In recent years, the overall scope of MAP3S has broadened geographically (to the entire United States) and the emphasis has shifted towards studies more directly related to acid deposition (Regional Acidity of Industrial Emissions - RAINE). This shift has paralleled the transfer of major funding for the project from the Department of Energy to the Environmental Protection Agency at the beginning of fiscal year 1980; support for the individual network site operations has remained with $\mathrm{DOE}$, however.

In addition to support of MAP3S/RAINE objectives, which are oriented toward atmospheric physics and chemistry research, the Network provides important information documenting regional deposition of common pollutants and acidity. These data form part of the recently instituted national effort aimed at monitoring precipitation chemistry and understanding trends therein. This effort is the result of increased awareness among the public and environmental policy makers of the potential environmental effects of fossil-fuel usage in power production, industrial activity, and transportation.

Precipitation chemistry data collected in serious research or monitoring projects should be of high quality, since measurements which eventually will be applied in support of environmental policy decisions must be defendable scientifically, with procedures standardized and well documented. A relatively high degree of skill is required in measurement of the rather ubiquitous chemical species of concern (including $\mathrm{pH}$, whose measurement appears deceptively simple). 
Therefore, the participants in the MAP3S/RAINE Precipitation Chemistry Network have summarized the Network's quality control procedures in this report, which hopefully will be a useful reference for those concerned about quality control and the comparability of quality among various sources of precipitation chemistry data. Quality of the Network's output has been of prime concern to the participants since early planning.

The most important aspects of quality control for a regional precipitation chemistry sampling network are listed below:

- the location of sites must meet well-stated regional sampling criteria,

- sampling and handling procedures must assure the chemical integrity of the samples prior to chemical analysis,

- laboratory analysis methods must be uniformly applied, and the calibrations sufficiently regular and well-documented, and

- all procedures should remain fixed throughout the duration of the project-in the event of necessary changes, studies of the comparability of methods must be conducted to ensure the comparability of output.

The balance of this report is a summary of the MAP3S/RAINE network's efforts to fulfill the above objectives, broken down into sections generally corresponding to the first three. The fourth point obviously applies to use of the network output to identify and study time trends in precipitation chemistry; observance of this requirement applies to all three of the sections, and note of procedure changes and comparison studies is made where appropriate. Although this report does not go into great detail in describing quality control procedures, some excerpts of written methods are provided in the Appendices, and reference is made to other reports which contain applicable details.

Table 1 is a listing of the persons who have contributed to this report 
directly, or indirectly through participation in planning of the Network and its procedures, or by faithfully observing the rules in field or laboratory activities. 
TABLE 1: MAP3S/RAINE Precipitation Chemistry Network

Quality Control Contributors

Name

Marc duBois

Raymond E. Falconer

John Kadlecek

Gerald Wolfe

Tom Butler

Gene Likens

Van C. Bowersox

Rosa dePena

John Takacs

James N. Galloway

William Keene

Geoffrey Parker

Donald Gatz

Bruce Komadino

Gary Stensland

John McNeil

Gilbert Raynor

Kurt Eastman

Lewis Fox

Tom Church

\section{Responsibility}

Site Operator

Site Manager (past)

Site Manager

Site Operator (past)

Site Operator

Site Manager

Site Operator (past)

Site Manager

Site Operator

Site Manager

Site Operator

Site Operator (past)

Site Manager (past)

Site Operator

Site Manager

Site Operator

Site Manager

Site Operator

Site Operator (past)

Site Manager

\section{Organization}

Atmospheric Sciences Research Center State University of New York/Albany

Department of Ecology and Systematics, Cornel1 University

Department of Meteorology

Pennsylvania State University

Department of Environmental Sciences University of Virginia

Illinois State Water Survey

Brookhaven National Laboratory

College of Marine Studies

University of Delaware 
TABLE 1

Page 2

Name

Gary Barret

John Klink

Robert Moore

M. Terry Dana

Dennis R. Drewes

Donald W. Glover

Jeremy M. Hales

Steven D. Harris

Jane E. Rothert

Vanessa Voegtlin

Donald Bogen

Herbert W. Feely

Herbert L. Volchok

Leroy Schroder

Robert W. Beadle

Dan Golomb
Responsibility

Site Manager (past)

Site Manager

Site Operator

PNL Project Manager

Computer Reporting

Equipment

MAP3S/RAINE Director

Technician (past)

Analytical Chemistry

Analytical Chemistry

External Quality Control

(past)

External Quality Control

(past)

External Quality Control

(past)

External Quality Control

Sponsor/Consultant

Sponsor/Consultant

\section{Organization}

Institute of Environmental Sciences/

Department of Geography

Miami University (Ohio)

Battelle, Pacific Northwest Laboratories

Environmental Measurements Laboratory Department of Energy

\section{U.S. Geological Survey}

Division of Biological and Environmental Research, U.S. Department of Energy

Office of Research and Development Environmental Protection Agency 
TABLE 1

Page 3

Name

Michael C. MacCracken

John M. Miller
Responsibility

MAP3S/Director (past)

Sponsor/Consultant

\section{Organization}

Lawrence Livermore Laboratory

Air Resources Laboratory/NOAA 


\section{SITE SELECTION AND VERIFICATION}

Locations of the eight current member sites are shown in Figure 1, and additional details are listed in Table 2. The sites were selected through consideration of the following criteria, and were located

- near individuals or centers with proven competency and interest in precipitation chemistry, and

- in areas where local sources (i.e. power plants, agricultural activities, industrial processes) do not affect the regional character of the precipitation composition, and

- collectively as a network so that coverage of the region (initially the northeastern United States) is uniform and dense enough to provide reasonable support for modeling, and reasonable assessments of regional pollutant deposition.

In essence, the second criterion requires that each site be representative of the sub-region of the network in which it is centered, and responsive to precipitation chemistry resulting from long-range transport and reaction processes. The success at meeting this criterion-for the first four sites at least-is documented by $\mathrm{Pack}^{l}$, who shows that the concentration of $\mathrm{SO}_{4}, \mathrm{H}^{+}$and to lesser extent $\mathrm{NO}_{3}^{-}$are uninfluenced by local sources.

Economic considerations are of course important in meeting the third criterion; the most desirable density of stations can never practically be obtained due to budgetary restraints. In principle, however, if the first two criteria are met, a relative few sites can serve to characterize the region. For the MAP3S/RAINE initial study region, it was fortunate that at least the major ionic species in precipitation were quite uniform over the region 1 (reflecting long-range processes). Additional support for the adequacy of the MAP3S/RAINE network comes from a comparative study of the MAP3S/RAINE network and a concurrently operating event sampling network in the same region ${ }^{2}$. 


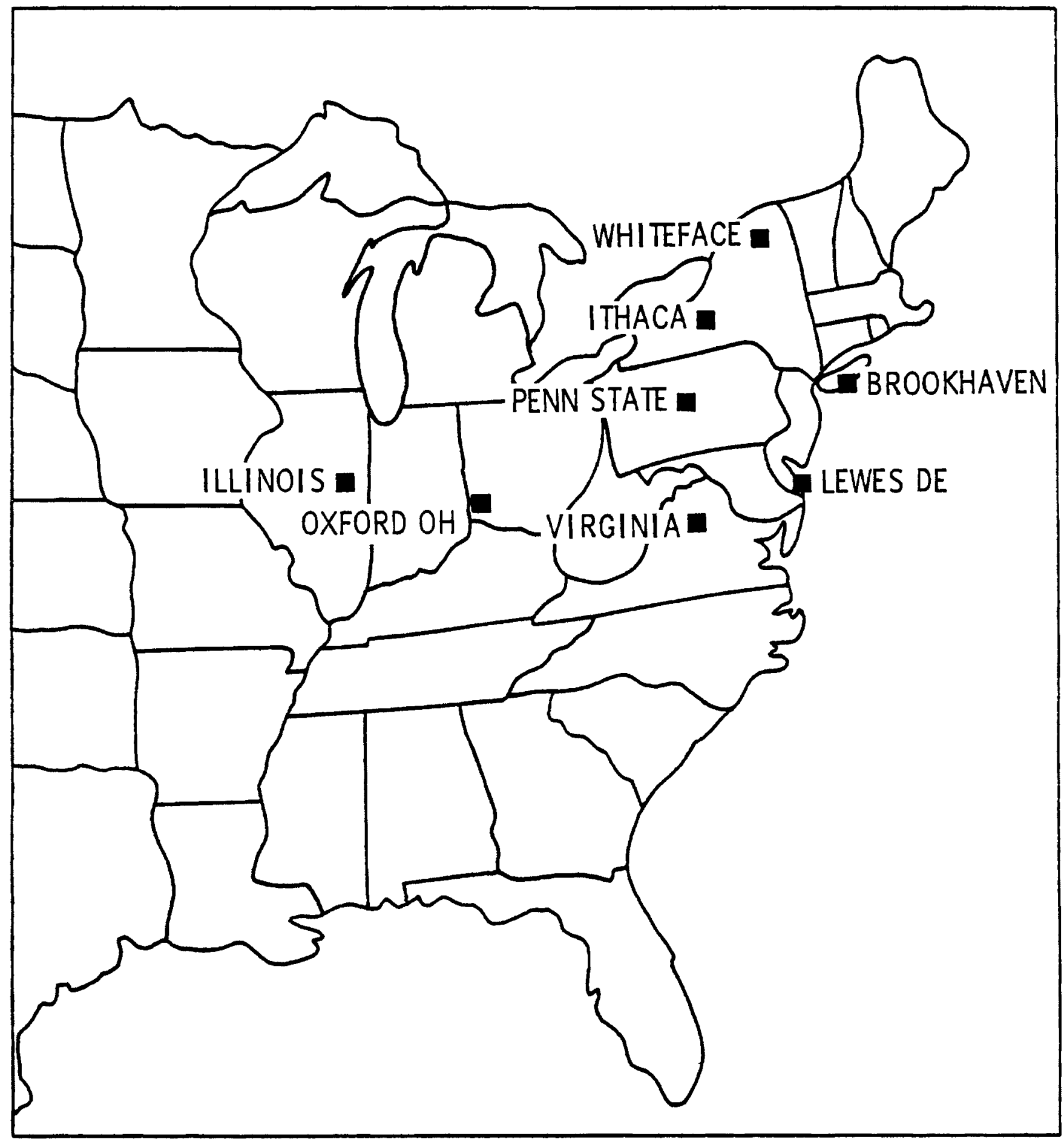

FIGURE 1: The MAP3S Precipitation Chemistry Network: Eight-Site Array

8 
TABLE 2: Network Site Details

\begin{tabular}{|c|c|c|c|c|c|}
\hline \multirow{2}{*}{$\begin{array}{l}\text { Site } \\
\text { No. }\end{array}$} & \multirow[b]{2}{*}{ Name } & \multicolumn{2}{|c|}{ Location } & \multirow{2}{*}{$\begin{array}{l}\text { Elevation } \\
(\mathrm{m}, \mathrm{ms}) \\
\end{array}$} & \multirow{2}{*}{$\begin{array}{l}\text { Date of First } \\
\text { Sample Collected } \\
\end{array}$} \\
\hline & & Longitude & Latitude & & \\
\hline 1 & WHITEFACE & $73^{\circ}, 51.5^{\prime}$ & $44^{\circ}, 23.5^{\prime}$ & 604 & October 11, 1976 \\
\hline 2 & ITHACA & $76^{\circ}, 43^{\prime}$ & $42^{\circ}, 23^{\prime}$ & 503 & October 26, 1976 \\
\hline 3 & PENN STATE & $77^{\circ}, 57^{\prime}$ & $40^{\circ}, 47^{\prime}$ & 396 & September 22, 1976 \\
\hline 4 & VIRGINIA & $78^{\circ}, 32.5^{\prime}$ & $38^{\circ}, 2.5^{\prime}$ & 171 & December 12, 1976 \\
\hline 5 & ILLINOIS & $88^{\circ}, 22^{\prime}$ & $40^{\circ}, 3^{\prime}$ & 213. & November 20, 1977 \\
\hline 6 & BROOKHAVEN & $72^{\circ}, 53^{\prime}$ & $40^{\circ}, 52^{\prime}$ & 24 & February 9, 1978 \\
\hline 7 & LEWES DE & $75^{\circ}, 0^{\prime}$ & $38^{\circ}, 46^{\prime}$ & 0 & March 1, 1978 \\
\hline 8 & OXFORD OH & $84^{\circ}, 44^{\prime}$ & $39^{\circ}, 32^{\prime}$ & 283 & October 1, 1978 \\
\hline
\end{tabular}


Once the general area is chosen, the selection of the exact site is influenced by a large number of considerations including

- location of overhanging objects near collector

- location of roads near collector

- location of point sources near collector

- location of non-point sources (plowed fields, salt marshes or lakes, etc.) near collector

- prevailing wind direction during precipitation events

- access to site during different seasons

- potential of land use changes after collector installation

- type of ground cover in collector area

- availability of power

In an effort to standardize the site selection process most of the above were defined in quantitative terms. As an example, the National Atmospheric Deposition Program site selection protocol is included in Appendix A. This protocol was primarily developed from the MAP3S/RAINE procedures and includes a more complete description of the above considerations.

\section{SITE VERIFICATION}

The verification that the selected sites did indeed collect precipitation representative of the region was done by two procedures. First the sites were visited by the other personnel of the MAP3S/RAINE Precipitation Chemistry Network to obtain a consensus as to whether the sites were suitable. Once the sites were approved, they were placed in operation. Second, to test this mechanism of site verification some sites (Delaware, Ithaca and Virginia) established satellite sites within a $5 \mathrm{~km}$ radius of the proposed site to determine the effect of some designated local sources (i.e. a road, salt marsh, agricultural field, etc.). In all cases the satellite sites confirmed that the initial sites selected collected precipitation that was uninfluenced by local sources.

Additional information and descriptions of several of the sites may be found in Network ${ }^{3-5}$ and MAP3S/RAINE ${ }^{6,7}$ reports. 
The collector that is used to sample the precipitation is a very critical part of any precipitation chemistry project. It must collect the precipitation in a quantitative, clean and representative manner. At the beginning of the MAP3S precipitation chemistry project, two studies had been completed on collector properties and intercalibration ${ }^{8-10}$. Using results from these studies and taking into corisideration some special requirements of the MAP3S program, the Battelle Collector was designed and constructed. Shown schematically in Figure 2, this collector was described in the first Network summary report. ${ }^{3}$ This report also contains the results of a comparison of its performance for event sampling with a previously accepted automatic design, the Health and Safety Laboratory (HASL) collector.

Table 3 lists dates of precipitation collector installations at the network sites, plus information relevant to later sections. Initial installations were performed by PNL personnel, and included setup and adjustment of the Battelle automatic collector and setup of raingauges provided by PNL, where required. * Each site--except for 0xford, Ohio--was visited again later for installation of the refrigerator component of the Battelle collector. A brief narrative of installation history follows.

August 1976. The first four sites of the network were initially outfitted on a single trip. The Whiteface and Penn State sites were initially permanent installations; at Ithaca, the collector platform was not completed, so a temporary installation was setup at the final site. The Virginia site was changed after initial setup--Virginia site personnel accomplished the equipment move.

October 1977. The Illinois collector was temporarily established at the University airport and was later moved by Illinois personnel to the final site.

November-December, 1977. The Lewes DE and Brookhaven collectors were set up and adjusted, but not permanently set at the final sites, which were not

*The Whiteface, Illinois and Brookhaven sites, being located adjacent to permanent meteorology stations, did not require additional raingauges. 
ready. The final setup was performed by local personnel.

April 1978. Two additional Battelle collectors were installed at the Penn State site, and all three (engaged in the collector comparison study) were outfitted with refrigeration units. The Brookhaven collector installation was similarly completed, at its permanent location.

May 1978. The remaining sites--except for Oxford, Ohio--received their refrigeration units; the Lewes $D E$ and Illinois sites were by this time in their permanent locations.

July 1978. The site at 0xford, Ohio, was initially and completely set up at its permanent location.

Table 2 lists dates of first sample collection at all sites. The delays between installation and sampling were due to delayed final site selection and preparation (usually installation of electric power) as noted above, and also because of shakedown equipment problems which were corrected locally upon consultation with PNL.

The collector comparison study mentioned above was inadequate in that variations among collectors of the same type were not studied. In addition, subsequent to the initiation of the MAP3S/RAINE network, two other major networks in North American began operating using different types of collectors. The National Atmospheric Deposition Program employs the HASL-type collector ${ }^{*}$, and the Canadian Network for Sampling Precipitation (CANSAP) uses a Canadian commerical unit. To establish the performance relationships among these units, a formal comparison study was conducted at the Penn State MAP3S/RAINE site. Three each of the three types were operated for event sampling for a nine month period. The results are detailed in a recent report ${ }^{11}$; the major conclusions were:

- The Battelle and HASL collectors compared favorably in concentration and deposition, while the Canadian type had significantly higher values for both;

\footnotetext{
${ }^{\star}$ Commercially produced version of the HASL collector.
} 
TABLE 3: Site Service and Inspection Chronology ${ }^{a}$

$\underline{\text { SITE }}$

\begin{tabular}{|c|c|c|c|c|c|c|c|c|}
\hline Date & Whiteface & Ithaca & $\begin{array}{l}\text { Penn } \\
\text { State }\end{array}$ & Virginia & Illinois & Brookhaven & $\begin{array}{l}\text { Lewes } \\
\mathrm{DE} \\
\end{array}$ & $\begin{array}{c}\text { Oxford } \\
\text { Ohio } \\
\end{array}$ \\
\hline August 1976 & I & I & I & $I^{b}$ & & & & \\
\hline February 1977 & & & & v & & & & \\
\hline October 1977 & V & & & & $I^{b}$ & & & \\
\hline $\begin{array}{l}\text { November- } \\
\text { December } 1977\end{array}$ & & & & & & $I^{b}$ & $I^{b}$ & \\
\hline April 1978 & & & $R, V$ & & & $R, V$ & $R, V$ & \\
\hline
\end{tabular}

May 1978

$R, V \quad R, V$

$R, V$

$R, V$

July 1978

June 1979

\footnotetext{
${ }^{a}=$ Initial installation of BNW Collector; $R=$ Refrigerator installation; $V=$ Site inspection and maintenance

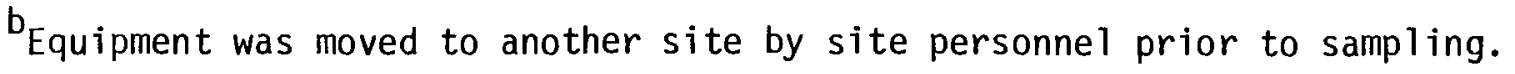


- The Battelle collector's collection efficiency was very close to that of a standard raingauge, the HASL was about 10\% more efficient, and the Canadian slightly less efficient.

An additional comparison study was performed at three MAP3S/RAINE sites, where event sampling with the Battelle collector was compared with weekly sampling with the HASL-type. The objective of this study was to establish the relationship in deposition between weekly sampling (NADP) and event sampling (MAP3S/RAINE). The result drawn from one year's data was that the weekly deposition weighted concentration was slightly but not significantly higher than the event-by-event value for the major ionic species 5 .

The Battelle collectors were not designed for long-term use on the MAP3S/ RAINE network, and were expected to be replaced eventually by commerical units. After more than three years service, for many of them, the Battelle collectors were phased out beginning January 1980. By the publication date of the present report, all sites should be operating with HASL-type collectors.

Field procedures for site operators, involving collector operation and maintenance, field data collection, and sample handling and shipping, are detailed in a site operator's manual. This manual is updated as procedures are modified and is a registered quality control document -- site operators are expected to certify that all activities are in accordance with the manual's instructions. The bulk of the site operator's manual is included in this report as Appendix B. In view of the phase out of the Battelle-designed precipitation collector, the section describing its operation has been omitted.

Table 3 shows dates of site inspections. These visits were associated with network meetings, installation of refrigerator units, or with special visits to correct chronic equipment problems. In general, site and laboratory facilities were inspected, and procedures reviewed. Actual sampling activities were not observed, however, due to timing of visits relative to precipitation events. No resources have been allocated specifically to cover travel and on-site time necessary for network management personnel to make these complete observations. 


\section{LABORATORY PROCEDURES}

Sample handling, chemical analysis procedures, and data logging/reporting are conducted in a methodical manner, with complete documentation on file for each step in the process. This system was established prior to operation of the network, and has been modified only in minor ways since. Basic procedures are outlined in the following paragraphs; more complete descriptions are contained in Appendix $C$.

SAMPLE ACCOUNTING AND HANDLING

Upon arrival of a shipment of samples from a site, an entry is started on the Sample Batch Chronology form (Figure 2). This form acknowledges arrival of identified samples on a given date, lists the events covered, and the sample "group" assigned. Receipt of the site operator's Debarkation Form (see Figure 4, Appendix B) allows completion of the Sample Batch initial information, including shipping date and confirmation that the samples sent were received. The Sample Batch form also evidences the commencement of chemical analysis, so that timing information (e.g., duration of shipping, period between sampling and shipping) is readily at hand.

Also, at the time of sample receipt, each sample is listed on an Analysis Checklist and Record form (Figure 3). The order of listing on these sequentially numbered forms ("groups") is chronologically within a site sample batch, and in the order of arrival. The resulting order becomes the order in which al1 regular samples* are analyzed, and subsequently reported. Each form has 20 rows, so that a "group"--numbered sequentially with prefix "PC"--contains 20 samples for analysis. These 20 sample bottles are kept together in a tray stored at refrigerator temperature at all times except during aliquoting for analysis.

*Special samples, e.g., Penn State collector comparison study samples, may be listed on separate analysis checklist forms. 
One row for each batch of samples arriving from a site.

Start entry on arrival date.

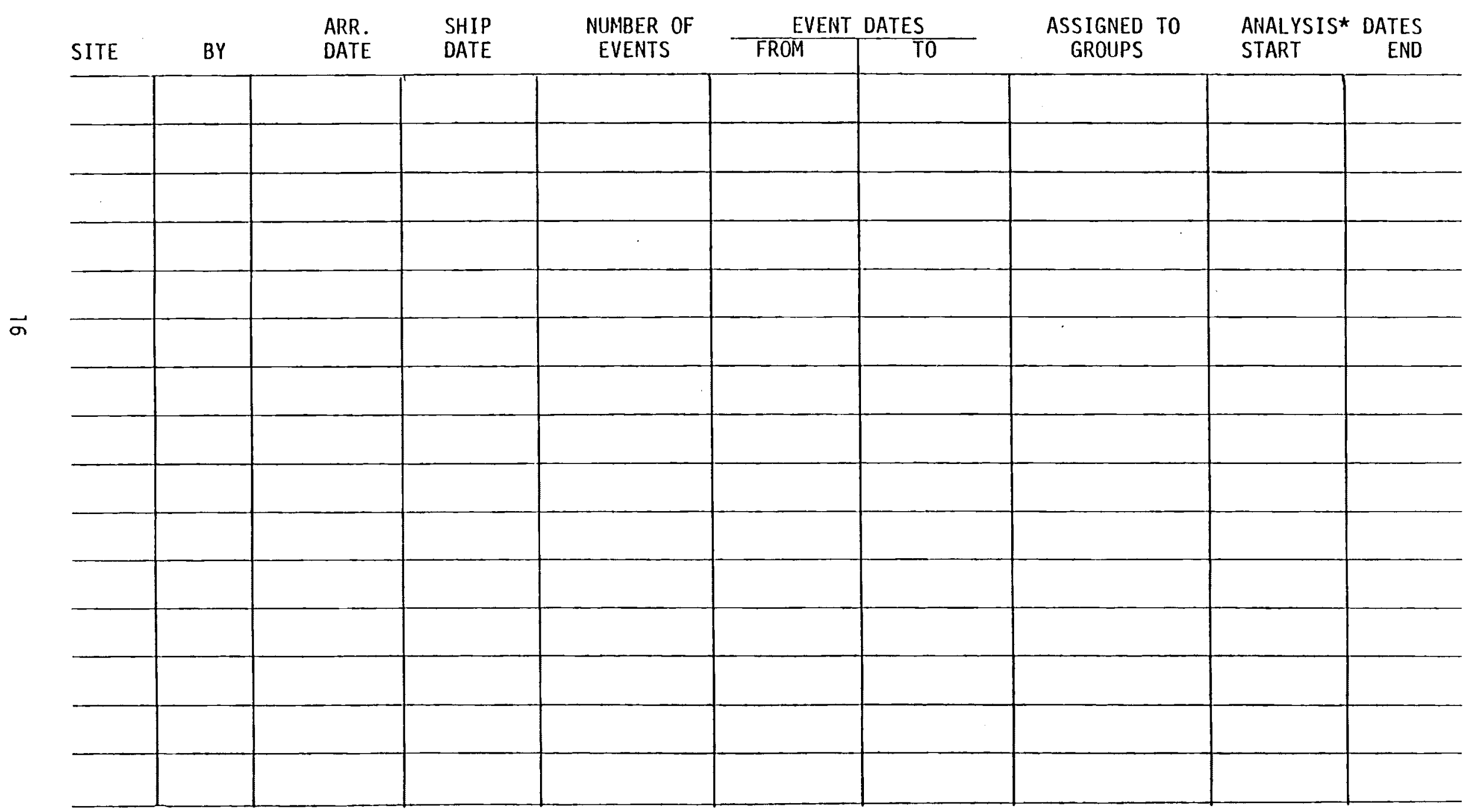

FIGURE 2: Sample Batch Chronology Form

* Not counting $\mathrm{SO}_{2}$ 


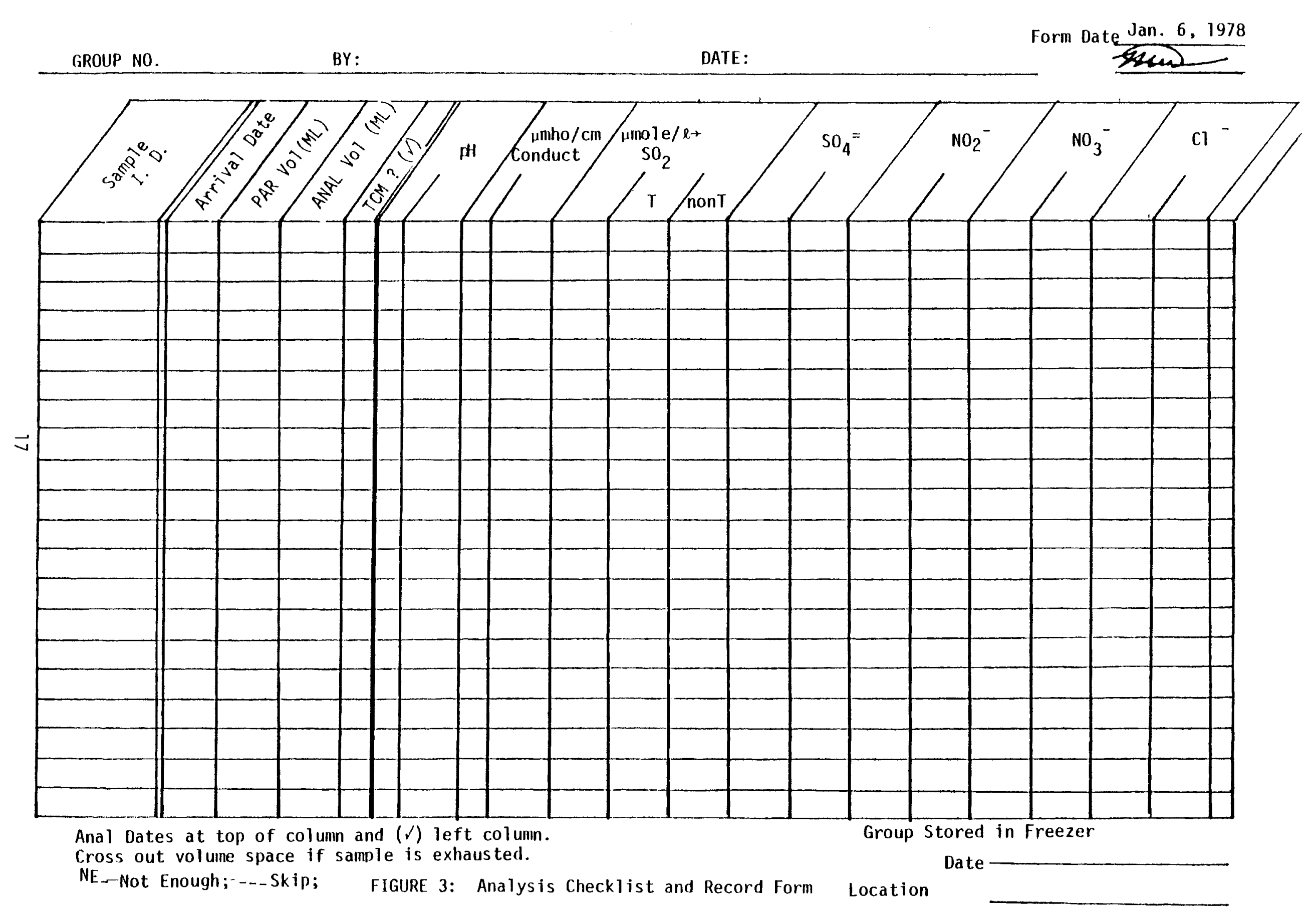


Group No.

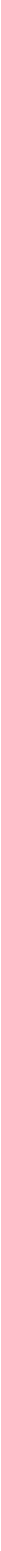




\section{CHEMICAL ANALYSIS DOCUMENTATION}

For each batch of samples analyzed by a particular method, calibration is documented on various calibration forms. These forms show approximate calibration constants, etc., confirming the initial validity of the analysis session. Final calibration constants and computations of concentrations are listed chronologically in Battelle, Pacific Northwest Laboratory books, which are catalogued holdings of the Battelle Technical Library.

The Analysis Checklist and Record (Figure 3 ) lists the date of analys is of each sample and the determined concentration in umoles/l. The analyst completes and enters the ion totals in $\mu$ eq/1 when each sample is fully analyzed.

Calibration standard solutions are prepared, in the case of the metals $\mathrm{Mg}$ and $\mathrm{Ca}$, by the Standards Laboratory of the Hanford Engineering and Development Laboratory. Standard solutions for the other chemical species are prepared by the analysts from reagent grade chemicals (dry). Although there are no systematic independent checks on these standards (except via intercalibration studies), standards are routinely prepared by alternate analysts to identify any preparation bias.

Changes of analysis methods are checked by extensive duplicate analyses using both methods prior to completing the change. Since the beginning of the Network, only the analysis method for $\mathrm{NH}_{4}^{+}$has been changed. The results of the comparison of methods for $\mathrm{NH}_{4}^{+}$are described in the First Periodic Summary Report ${ }^{3}$.

\section{DATA LOGGING}

Upon arrival of a sample and its assignment to a group via the Analys is Checklist form, a computer file for the sample is opened. This process employs a FORTRAN program called GRPIN, which is assessed interactively by remote terminal. GRPIN establishes files corresponding to group numbers containing 20 or more samples; each sample file has spaces for the 28 "species" recorded and eventually reported on data reports (bimonthly, summary ${ }^{3-5}$, and the MAP3S Data Bank tape). When available, field data from the site (Field Data Log form, Figure 5, Appendix B) are added and finally, when chemical analyses are com- 
plete, concentrations are entered.

The primary data verification (check for errors in transfer of data from form to form) is through independent ion balance calculations by the analyst and the GRPIN program. When several sample groups are completed and checked, they are combined and edited using other programs into a bimonthly data report file. This file is used to update Data Bank tapes, and a hard copy is reproduced for bimonthly distribution.

\section{DUPLICATE ANALYSES}

All routine reanalyses of samples are logged and periodically reported under a special Quality Control Sample "site" designation. Most duplicate analyses are conducted with the ion chromatograph species, as frequently peaks are missed on one or more species. This required reanalysis of all species on a chromatograph scan, resulting in duplicate data. Deliberate reanalyses are also conducted periodically to correct ion balance discrepancies, and special studies of sample aging are occasionally done. Data from the latter are included in Periodic Summary Reports ${ }^{3-5}$.

\section{COLLECTION EQUIPMENT PREPARATION}

To ensure consistently clean sample containers (shipping and collection bottles and buckets) in use on the Network, all sample-contact materials are prepared and precleaned at the Battelle, PNL Laboratory. The procedures for cleaning bottles and HASL-type collector buckets are included in Appendix C. The bottle method has been tested by comparison with other cleaning methods early in the Network history. 3,4 . The method for cleaning buckets is that used by the central laboratory of the NADP ${ }^{12}$.

\section{EXTERNAL LABORATORY QUALITY CONTROL}

The MAP3S/RAINE network laboratory participated in a laboratory intercalibration study conducted by the Environmental Measurements Laboratory (EML) of the Department of Energy. Results of this study have been reported ${ }^{13}$ and the Battelle, PNL relevant results included in the Third Periodic Summary ${ }^{5}$. 
EML also supervised an external quality control system which included blind analyses of samples delivered to the Battelle, PNL laboratory from the sites. The samples included standard precipitation samples (previously analyzed by EML) and duplicates of actual MAP3S/RAINE network samples. Battelle, PNL laboratory personnel were unaware of the actual identity of these samples, and were uninvolved in the process except in submission of the data to a disinterested party (for removal of quality control sample results) prior to reporting. Full results of this study, which was terminated December 1979, are to be found in the Third Periodic Summary 5 .

A similar external laboratory quality control program was begun in June 1980, under the supervision of U.S. Geological Survey personnel. Except for slight modifications (due to the different nature of MAP3S/RAINE network sampling) the procedure is identical to that employed for NADP. 


\section{REFERENCES}

1. Pack, D. W. "Sulfate Behavior in Eastern U.S. Precipitation, "Geophys. Res. L., $5(8):$ 673-674, 1978.

2. Pack, D. H. "Precipitation Chemistry Patterns: A Two-Network Data Set," Science, 208: 1143-1145, 1980.

3. The MAP3S Precipitation Chemistry Network: First Periodic Summary Report (September 1976-June 1977), PNL-2402, Battelle, Pacific Northwest Laboratories, Richland, WA, 1977.

4. The MAP3S Precipitation Chemistry Network: Second Periodic Summary Report (July 1977-June 1978), PNL-2829, Battelle, Pacific Northwest Laboratories, Richland, WA, 1979.

5. The MAP3S Precipitation Chemistry Network: Third Periodic Summary Report (JuTy 1978-December 1979), PNL-3400, Battelle, Pacific Northwest Laboratories, Richland, WA, 1980.

6. MacCracken, M.C., ed. The Multistate Atmospheric Power Production Pollution Study - MAP3S: Progress Report for FY 1977 and FY 1978, DOE/EV-0040, U.S. Department of Energy, Office of Health and Environmental Research, Washington, D.C. (Available from NTIS, Springfield, VA).

7. MAP3S/RAINE Program Design-Basis Document, PNL-3424, Battelle, Pacific Northwest Laboratory, Richland, WA, 1980.

8. Berry, R. L., D. M. Whelpdale and H. A. Wiebe. An Evaluation of Collectors for Precipitation Chemistry Sampling. Presented at the WMO Expert Meeting on Wet and Dry Deposition, AES, Downsview, Canada. 17-21 November 1975.

9. Galloway, J. N. and G. E. Likens. "Calibration of Collection Procedures for the Determination of Precipitation Chemistry," Water, Air and Soil Pollution, 6, 241, 1976.

10. Galloway, J. N. and G. E. Likens. "The Collection of Precipitation for Chemical Analysis," Tellus 30, 1, 1978.

11. de Pena, R. G., J. A. Pena, and V. C. Bowersox. Precipitation Collectors Intercomparison Study, Final Report-Contract No. 1416309, Department of Meteorology, The Pennsylvania State University, University Park, PA, 1980.

12. Stensland, G., Private Communication, Illinois State Water Survey, Urbana, IL, 1980.

13. Bogen, D. C., S. J. Nagourney, and G. A. Welford. MAP3S Precipitation Chemistry Intercomparison Study, EML-341, U.S. Department of Energy, Environmental Measurements Laboratory, New York, NY, 1978. 


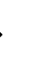

- 


\section{APPENDICES}

\section{CONTENTS}

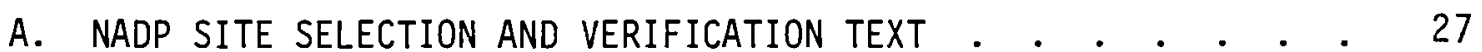

B. SITE OPERATOR'S MANUAL (EXCERPTS) . . • . . . . . . . . . 35

C. LABORATORY QUALITY CONTROL PROCEDURES (SELECTED) . • • . • • 61

D. EXTERNAL LABORATORY QUALITY CONTROL: SUBMISSION

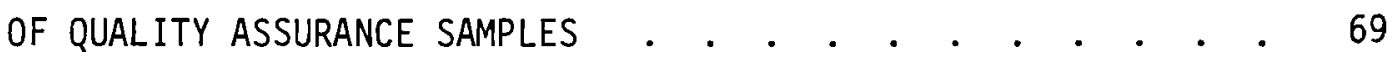


.

. 
APPENDIX A

NADP SITE SELECTION AND VERIFICATION TEXT*

*Excerpted from "Site Selection and Certification", a report of the National Atmospheric Deposition Program 


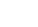


Site Selection and Certification

\section{INTRODUCTION}

A change in the chemical composition of precipitation is a good indicator of changes in atmospheric composition since precipitation is a very good scavenging agent of many atmospheric substances (both solid and gaseous). The nutrient status, growth, and development of plants on land and in surface waters are influenced by the availability of beneficial nutrient elements and the deposition of injurious substances dispersed in the atmosphere. Similarly, the health and reproductive capacity of domestic and wild animals, and fish populations are influenced by atmospheric constituents.

Previously, it was believed that most nutrient elements essential for the growth of plants were obtained after release from decomposing organic matter, weathering of soil minerals, or addition as fertilizers. It is now recognized that substances deposited in precipitation, and as dry particulate matter and aerosols significantly augment the supply of both essential elements and potentially injurious substances.

Since the amount of substances dispersed in the atmosphere and deposited in precipitation, particulate matter, and aerosols is projected to increase, there is an increasing need for careful measurement of the amounts, nature, and biological effects of these substances. Such measurements are essential for responsible management of the agricultural, forest lands, and aquatic ecosystems of the United States and Canada. A total of approximately 40 
precipitation collection sites are planned to be established in the U.S., primarily in the eastern two-thirds of the nation, to provide observational data for topical research on precipitation chemistry.

\section{SITE SELECTION}

The collection sites for the Network will be selected to give accurate and representative information concerning the temporal and spatial variation of precipitation and dry particulate deposition of important chemical constituents. The location of individual sites will be chosen to represent major physiographic regions and major agricultural, aquatic, and forested areas within each cooperating state and region. It is important that local sources not bias a sample by locating it next to a point or line source of contamination not representative of the region. However, if a region is typified by a certain type of agricultural land use or is in a heavily industrialized region, the sampler should be located within this region to provide representation of such extensive pollution sources.

The sampler should be sited to conform as nearly as possible with the following criteria:

1. No moving sources of poliution, such as routine air, ground, or water traffic shall be wthin 100 meters of the site.

2. No surface storage of agricultural products, fuels, or other foreign materials shall be within 100 meters of the site.

3. No continuous sources of pollution shall be within 50 kilometers in the direction of the mean wind direction for the site, and 30 kilometers in all other directions.

4. Sampler shall be installed over undisturbed land, preferably grass covered with no objects within 5 meters of the sampler. 
5. No object shall project onto the sampler with an angle greater than $30^{\circ}$ from the horizontal. Give particular attention to overhead wires.

It may not be possible to meet all of the above criteria at individual sites. The questionnaire which is described in the following paragraphs will clarify the degree of departure from the desired site requirements.

\subsection{Site Description Questionnaire}

A site Description Questionnaire covering the important points to consider for either selecting a new site or evaluating an existing one has been formulated and attached. The following paragraphs discuss each topic covered in the questionnaire. All measurements should be reported in the metric system and directions in degrees from north or 16 points of the compass. Throughout the questionnaire when a distance is requested the distance from the collector should be inserted. If additional space is needed for extended remarks concerning local problems, please attach additional pages. This form should be completed for each active or potential site and returned to the NC-141 Director as soon as possible.

\subsubsection{A. Site Identification}

The station name should be descriptive and unique. Numbers for each site will be assigned later. The elevation should be that of a specific object at the site. The needs for the requested information are obvious. The mailing address should be clear to facilitate information and data transfer between the project administration, central analytical laboratory, and the field observing participants. 


\section{$2.1 .2 \quad$ B. Logistics}

These questions are very important for the continued operation of a quality site. While not necessary, it is also desirable to provide a simple hand drawn map showing the relative location of the site to roadways and the nearest electricity transmission lines.

\section{$2.1 .3 \quad$ C. Equipment on Hand}

The raingage is strongly recommended to provide concurrent measurement of precipitation. Specifically, the recording raingage allows the added feature of determining precipitation rates needed to interpret the deposition observations. Similarly, a wind recorder will allow correlation between observed precipitation chemistry and wind speed and direction. The $\mathrm{pH}$ and conductivity meters are essential for preliminary assessment of the sample chemical quality.

\section{$2.1 .4 \quad$ D. Background Data}

The climatology of the area, as interpreted for the local site, will be useful to ascertain the regional representativeness of the location. As records are accumulated, the site climatology will be continuously updated and compared with nearby long-term records to detect anomalous behavior.

\subsubsection{E. Topography}

Careful evaluation of these items will determine the sampling quality of the site. The surface grade should be reported in percent positive upward and negative downward in various directions from the sampler site. If available, soil analyses close to the site will be useful to characterize the site environment. The description of physical objects in proximity to the site will permit evaluation of potential sample contamination for wind-blown precipitation. 


\subsubsection{F. Civilization}

The questions are designed to differentiate between ground, air, and water moving sources. Stationary source locations are required to ascertain their potential influence on precipitation quality. Unusual or intermittent sources such as quarry operations, stockpiles of coal, farm wastes, and similar materials should be recognized as potential sources of contamination under high wind conditions.

\section{GENERAL SITE REQUIREMENTS}

The sites will be evaluated on the basis of available knowledge of wind trajectories, sources of substances in the atmosphere, prevalent forms of deposition, frequency of precipitation events (rain, snow, hail, and dust storms), and other meteorological and atmospheric processes that influence the deposition of substances in each state or region. Of critical importance at the local scale is the proximity of the collector to obstacles (disturbances to airflow around the collector opening) and consideration of land-development in future years. Since it is many times not possible to predict future landuse change, consideration should be given to alternate sites in the event that the original selection is no longer representative of the region. The collection stations should be sited, whenever possible, in the proximity to locations where research on either water resources, management, quality, or distribution is ongoing. Such judicuous placement of collectors will allow additional use of the Network data by those with a direct need for the information. 


\subsection{Site Classification and Certification}

Each site will be initially classified and certified as promptly as possible, based upon the information in the questionnaire and, if necessary, a site visit. A final certification will be made after a year or more of routine operation of each site.

Classification will be at four levels:

Class $A$

1. Required wet/dry collector and weighing rain gauge on site.

2. Acceptable pH and conductivity instruments on site.

3. All logistical, topographical and local source criteria are satisfactory.

4. Recording wind speed and direction instruments on site.

\section{Class B}

The same as Class $A$, but lacking wind instruments.

Class C

The same as $C$ lass $A$, but unsatisfactory (or uncertain) of logistical, topographical or local source criteria.

Class D

The same as $C$ lass $A$, but lacking wind instruments and also unsatisfactory (or uncertain) of logistical, topographical or local source criteria.

\section{FIELD OBSERVER INSTRUCTIONS}

A manual is provided for each observer to establish uniform procedures for sample handling and reporting. It is anticipated that revisions will be necessitated by field experience and will be issued periodically. The Instructions are prepared in such a way that numbered revisions can be easily inserted to keep the manual current at all times. 
APPENDIX B

SITE OPERATOR'S MANUAL (EXCERPTS) 
.

. 
THE MAP3S/RAINE PRECIPITATION CHEMISTRY NETWORK

SITE OPERATOR'S MANUAL

\section{CONTENTS}

page

1. Introduction 1

2. Battelle Northwest Automatic Precipitation Collector 3

3. Routine Sample Collection - BNW Collector 17

4. Laboratory Treatment of Samples 21

5. Division and Shipment of Samples 24

6. Data Logging 26

7. Special Sampling Procedures 31

8. Routine Sample Collection - ACM Collector 35

9. Rainfall Measurement 37

MAP3S Precipitation Chemistry Network Site Operator's Manual, Revision 3, by M. Jerry Dana, September 1, 1980, page 2 of 41. (sint) 


\section{INTRODUCTIOI:}

This book is intended as a guide to MAP3S Precipitation Chemistry Network site operation. The procedures described have been developed over four years of network formation and operation, and represent the level of effort required of site operators as of the cover update. These procedures were developed in response to the initial, and subsequent evolving objectives of the MAP3S project - updates of the complete manual are accomplished periodically but in the meantime, site operator's memoranda involving procedure charges are issued, and should be inserted in the appropriate sections.

The network management has done its best to incorporate all necessary information; any ambiguities or incompleteness should be reported to the appropriate persons below. Site operators are urged to consuit us whenever questions arise, and communicate any suggestions bearing on improvements to this manual or smooth operation of the network. 


\section{CONTACTS}

Subject

Battelle Collector Maintenance

Site Supply Needs

Data Logging,

Procedure Questions/

Suggestions

Laboratory/Chemistry

Commercial-Product

Collector Maintenance
$\operatorname{Person}(\mathrm{s})$

Donald W. Glover

M. Terry Dana

M. Terry Dana

Jane E. Rothert

Manufacturer

(Inform T. Dana)
Address/Phone

Battelle Pacific Northwest Laboratories

P.0. Box 999

Richland, WA 99352

509-373-2861

FTS 440-2861

(same)

(same)

(same)

See operator's manual

MAP3S Precipitation Chemistry Network Site Operator's Manual, Revision 3, by M. Terky Dana, September 1, 1980, page 4 of 41. 


\section{ROUTINE SAMPLE COLLECTION - BNW COLLECTOR}

\section{A. SUPPLIES TO TAKE TO SITE:}

1 New collection bottle ( $1 / 2$ or 1 gallon) with cap attached, bagged

2 New sampler lid covers, bagged

1 New rinse collection bottle (2 quart) with cap attached

1 Spare clean funnel, in sealed bag

1 Wash bottle, with at least 2 liters of deionized water

1 Clean, dry cloth

1 Allen wrench for lid set screws

Operation Manual for Sampler

\section{B. STATUS INSPECTION}

Check to see if the green light is lit (power to sensor head)*. If so, and the lid is open though there is no precipitation falling, check the sensor plates for some obstruction. If the sensor grids are merely wet, wait for them to dry off and the collector lid to close. If it does not close, though dry, proceed with regular procedure and inform BNW. (Note lid operation record for duration of open phase.)

\section{C. DEACTIVATION OF AUTOMATIC OPERATION}

1. Unlock and remove sampler housing door. CAUTION: Stay clear of door path during all times when the sampler mode switch is set to AUTOMATIC.

2. Set sampler mode switch to OFF. (Leave main power switch ON.)

3. Inspect the sensor grids for debris, and the external bolts on the lid mechanism for looseness (see the Operation Manual). Check the seal of the lid to the funnel top. If loose or too tight, inform Battelle.

*Not on new units (Sites 5-8)

MAP3S Precipitation Chemistry Network Site Operator's Manual, Revision 3, by M. Terry Dana, September 1, 1980, page 19 of 41. 
3.D. MANUAL OPENING OF LID

1. Staying clear of lid path, set sampler mode switch to OPEN.

2. Allow lid to completely open and the motor stop.

3.E. LID COVER REMOVAL

Remove the plastic lid cover and discard.

\section{F. REMOVING SAMPLE COLLECTOR BOTTLE}

1. Carefully unscrew the collector bottle from the Teflon connector, simultaneously lowering the lab jack.

2. When the bottle is free, immediately attach the cap which has been stored in a plastic bag in the collector housing, or brought from lab.

3. Mark the bottle with the time of day and collection date and secure for return to the lab.

CAUTION: Do not write over frost or dew. Dry the area with vigorous rubbing with a cloth before marking, if necessary.

3.G. FUNNEL RINSE (NO REPLACEMENT OF FUNNEL ONLY):

1. Uncap the rinse bottle (two-quart) and attach to connector, adjusting lab jack to just support the bottle. Put the cap in a clean plastic bag during rinse.

2. Use the wash bottle of deionized water to rinse the interior surface of the funnel with approximately 2 liters of water.

MAP3S Precipitation Chemistry Network Site Operator's Manual, Revision 3, by M. Texry Dana, September 1, 1980, page 20 of 41. 
Note any visible matter either washed off or not. Be careful to not contact the water with anything exterior to the inner funnel surface.

3. Remove the rinse bottle in the same manner as that for the precipitation sample bottle. Mark the rinse bottle with the sample I.D. and secure for return to lab.

\section{H. PLACEMENT OF FUNNEL}

Follow this procedure only if the funnel is to be laboratory cleaned for snow sampling, or if it is damaged.

1. Remove the Teflon connector and store in a clean bag (marked with the sample number if appropriate).

2. Put a clean lid cover over the funnel mouth.

3. Handling the funnel only by the exterior flange, lift the funnel out of the sampler and place in a clean large plastic bag. Mark the bag with the sample number if appropriate.

4. Reverse the procedure for placement of new funnel.

3.I. PLACEMENT OF NEW PRECIPITATION COLLECTOR BOTTLE

1. Remove the new collector bottle ( $1 / 2$ or 1 gallon) from its bag and, before removing the cap, mark it with the sample ID (less collection date) and the time of day. Remove the cap with the small bag attached. This will result in the cap remaining in the bag for storage during sampling.

2. Screw the collector bottle to the funnel connector snugly and adjust the lab jack so it will be supported. Don't raise the labjack so much that the funnel is lifted.

3. Check to see that the funnel is still firmly seated on its sleeve.

3.J. MANUAL CLOSING OF LID

1. Remove a new lid cover from its bag and place on the lid, making sure that it is on smoothly around the edge of the lid.

MAP3S Precipitation Chemistry Network Site Operator's Manual, Revision 3, by M. Ierry Dana, September 1, 1980, page 21 of 41. TAS 
2. Staying clear of the lid path, switch the sampler mode switch to OFF. Allow the lid to close completely and the motor stop.

3. Inspect the lid closure area to see if the seal is tight, and that the cover is not bunched up.

3.K. REACTIVATING AUTOMATIC OPERATION

Switch sampler mode switch to AUTOMATIC. Don't forget this! NOTE: If the sensor grid is wet, the lid will reopen. (It is preferable to wait until the grid is dry before sample changing.)

3.L. DATA LOGGING AT SAMPLE COLLECTION (SEE SECTION 6 FOR FURTHER DETAILS)

1. Note air temperature if a thermometer is available. Otherwise, use any convenient reading for the approximate collection time.

2. Check the rain guage record for rain start and stop times, and sampler lid operation record for lid operation times. Interpret the latter as to lid open and closed times. Note any discrepancies from expected behavior.

3. Replace rain guage and lid operation charts (if it is time, weekly).

4. Fill out field log book entry and check to see that samples are properly marked.

5. Close and lock sampler door.

MAP3S Precipitation Chemistry Network Site Operator's Manual, Revision 3, by M. Terry Dana, September 1, 1980, page 22 of 41. (and Dana, 22 of 41 . 


\subsection{LABORATORY TREATMENT OF SAMPLES}

4.A. RAIN SAMPLES

1. Measure Volume of Sample

Weigh the precipitation sample bottle with cap attached on a suitable scale -- accuracy to within a few arams is auite adequate. Record net volume in log book and mark on sample bnttle.

2. Measure $\mathrm{pH}$

1. Open the precipitation sample bottle carefully and pour off the minimum volume needed into a suitable clean container.

2. Immediately reclose bottle.

3. Determine $\mathrm{pH}$ using $\mathrm{pH}$ meter operating procedures ard record in a $\log$ book, along with approximate temperature of aliquot.

4. Discard aliquot.

5. Repeat steps 1-4 for rinse sample.

3. Temporary Storage

If the samples are to be stored prior to division for shipment, place in refrigerator, with cap on tight.

4. Secure Copies of Event Recorder Charts

If the recorder charts have been changed (weekly) make Xerox copies of same, or otherwise record the information thereon to be filed for mailing to $\mathrm{BNW}$.

5. In the Event of Problems

Call BNW if any problems have come up which require immediate attention.

4.B. SNOW SAMPLES (COLLECTOR NOT EQUIPPED WITH FUNNEL HEATER)

1. Take the bagged funnel with sample bottle attached, remove from the bag and stand it up so that the melting snow will drain into the bottle.

2. Allow the snow to melt into the bottle at room temperature

MAP3S Precipitation Chemistry Network Site Operator's Manual, Revision 3, by M. Terry Pana, September 1, 1980, page 23 of 41. 
3. Remove the bottle and treat it as described in the sampling procedure manual.

4. Perform funnel rinse as in section 3 , and rebag for the next time.

4.C. TCM-DOPED SAMPLE ALIQUOTS

\section{C.1 Equipment}

- 1 ounce poly bottles

- 0.2 M TCM Solution

\section{C.2 TCM Solution}

Dissolve $54.4 \mathrm{~g}\left(0.2\right.$ mole) of $\mathrm{HgCl}_{2}$ (mercuric chloride) and $23.4 \mathrm{~g}$ ( $0.4 \mathrm{~mole}) \mathrm{NaCl}$ in 1 liter of distilled water. You may wish to scale this down to 100,250 , or $500 \mathrm{ml}$ if convenient, since only 1 or $2 \mathrm{ml}$ are required for each sample. WARNING! This solution is highly poisonous - if spilled on skin flush with water. Follow the established procedures of your laboratory for handling and disposal of waste.

No special precision in weighing out these chemicals is required, since the solution required for doping is approximately the minimum needed to fix the expected amount of $\mathrm{SO}_{3}=$ in the sample. The amount of mercury complex formed will depend on the amount of sulfite (unknown) in the sample, and there will be an excess of TCM.

\section{C.3 Doping Aliquots}

Immediately after returning the rain samples

(do not use this procedure on BNW funnel rinses) to the laboratory - presumably at the time of $\mathrm{pH}$ measurement, place about $1 \mathrm{ml}$ of the TCM solution per $10 \mathrm{ml}$ of aliquot in a fresh vial. Use a $20 \mathrm{ml}$ (approximate) aliquot of the sample if available, but not less than $10 \mathrm{ml}$, as we require about 10 $m l$ for the sulfite analysis. Place the sample aliquot in the vial with TCM and close the vial.

A preferred way to administer the TCM would be to use an automatic pipetter or an Eppendorf or similar pipette (disposable tips). This will help to avoid contamination of the area with mercury, and avoid washing up, etc. 
Record the TCM and sample volumes on the data log forms in the blank row as follows:

$\underbrace{\begin{array}{c}\text { Added TCM, / Total Aliquot } \\ \mathrm{ml}\end{array}}_{\mathrm{ml}}$

Send a blank vial of $10 \mathrm{ml}$ of TCM solution you are using periodically. Mark with the date you draw it. Maintain $\mathrm{SO}_{2}$-free environment for TCM solution and fixed samples.

Do this procedure in an area away from the normal "clean" area of your $1 \mathrm{ab}$, since the TCM contains a lot of potentially contaminating $\mathrm{Na}$ and $\mathrm{Cl}$.

Keep the vials reasonably clean, but the high level of cleanliness required for the other shipping containers is unnecessary, since the TCM solution is quite concentrated, and essentially nothing will interfere with the sulfite analysis.

Seal bottles with caps tight and plastic tape.

MAP3S Precipitation Chemistry Network Site Operator's Manual, Revision 3, by M. Terpy Dana, September 1, 1980, page 25 of 41. SA 


\section{DIVISION AND SHIPMENT OF SAMPLES}

\section{A. DIVISION}

1. Find a clean working area with lots of elbow room.

2. Select the appropriate number of 8-oz. shipping bottle(s) for each precipitation sample to be divided, according to the following protocol:

$\begin{array}{cc}\text { Sample volume * } & \text { Volume Shipped } \\ (\mathrm{ml}) & (\mathrm{ml}) \\ \sim 20-250 & A 11^{\star} \\ 250-\sim 750 & 250 \\ >\quad \sim 750 & 500\end{array}$

* After pH measurement

3. Mark the appropriate shipping bottles with all the information found on the collector bottle. (I.D., in and out times, sample volume).

4. Remove the caps from both bottles and set them aside in a clean area.

5. Carefully pour the sample aliquot into the shipping bottle, trying to keep the stream from touching the lip of the shipment bottle mouth. Fill the shipping bottle to about $1 / 2$ inch below the neck.

6. Replace the caps.

7. Dry the exteriors of the bottles if necessary. Note integrity of markings and refresh if necessary.

8. Seal the cap of the shipping bottle with white plastic tape provided.

9. Prepare the shipping bottles for shipment if it is time (one month or three events, whichever first)

MAP3S Precipitation Chemistry Network Site Operator's Manual, Revision 3, by M. Terry Dana, September 1, 1980, page 26 of 41. 


\section{B. SHIPMENT}

1. Place the shipping bottles for the month (or sooner if there are 3 events) in a shipping container and secure it carefully.

2. Fill out an embarkation form. (see Section 6)

3. Mail the shipping embarkation form (or equivalent) along with copies of the raingauge and lid operation charts and a copy of the week's logbook entry, to:

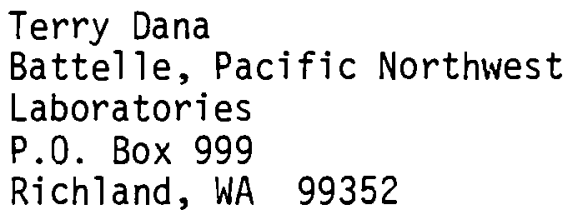

4. Check the address label on the shipping container for readability.

5. Ship samples air freight collect to:

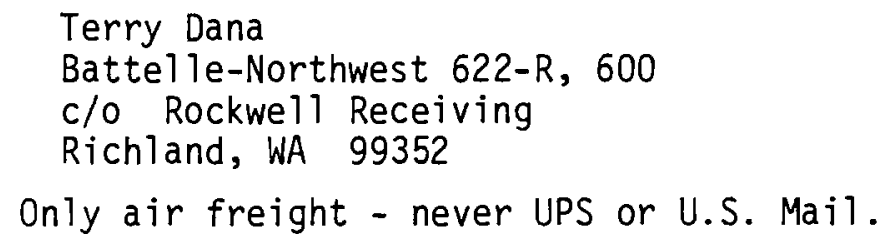

6. Do not send U.S. mail addressed to "c/o Rockwell Receiving." 
6. DATA LOGGING

\section{A. SAMPLE IDENTIFICATION}

Sample collection bottles (or buckets), and sample shipping bottles are marked with the sample I.D. number, which is that used for identification of the sample's chemical concentrations and other data on reports.

This number is of the form:

\section{$\underline{M} \underline{M} \underline{D} \underline{D} \underline{S} \underline{I}$}

where

MM is the month (01 for January, etc.)

DD is the day of the month (01, 02, etc.) of collection

$S$ is the site number

$$
\begin{array}{ll}
1 \text { - Whiteface } & 5 \text { - Illinois } \\
2 \text { - Ithaca } & 6 \text { - Brookhaven } \\
3 \text { - Pennstate } & 7 \text { - Lewes, DE } \\
4 \text { - Virginia } & 8 \text { - Oxford, } \mathrm{OH}
\end{array}
$$

$T$ is the sample type

$$
\begin{aligned}
& 0 \text { - Event } \\
& 1 \text { - Other sample type (identify on D.L. form) } \\
& 3 \text { - BNW Funnel rinse }
\end{aligned}
$$

In and out times of day ( $z$ ) should be written on the bottle along with sample volume. (Please write the " $z$ " to be sure you haven't mistakenly used EDT or EST.)

- Get the proper date of collection. This means you can't write the date on the number until you collect the sample. The printouts use collection date to identify the sample.

- Don't get the sample type "T" numbers mixed up.

MAP3S Precipitation Chemistry Network Site Operator's Manual, Revision 3, by M. Terfy Dana, September 1, 1980, page 28 of 41. past 


\section{B. SHIPPING EMBARKATION FORM}

At the time of shipping samples, fill out this form and mail as instructed in Section 5. Of particular importance are the following:

Date of Shipment - We need to know the time of transit, so list your date that the samples are delivered to the shipper. Name of Shipper - Please sign for quality accountability purposes. Total numbers of boxes and bottles shipped and numbers of bottles and boxes remaining on hand.

Make one entry in table for each event sample or weekly sample. Leave no Spaces Blank

\section{C. DATA LOG FORM}

At the time of shipping, mail this form as well. The data should be collected as soon as possible and filled in. Please LEAVE NO BLANK SPACES - explain any gaps

Date - This is the date of mailing of form Site Operator - Sign to confirm samples handled under proper procedure.

Date/Time Set out - This is the start of the sampling period. It should be exactly the date and time of collection of the previous sample for that collector, unless the collector was out of service. This information is used to calculate "Down Time", which is important for determining the reliability, etc., of the collector. (Log sample time and down time). Any down time should be explained in the "remarks" space particularly if an event is missed.

Don't put the start of precipitation in this space! List that below in the proper row.

Remember: Times of day are GMT or " $Z$ " time. 
MAP 3S PRECIPITATION CHEMISTRY NETWORK

SHIPPING EMBARKATION FORM (ATTACH COPY OF LOGBOOK ENTRIES)

Site NAME and NUMBER

Date of Shipment

Name of Shipper

(please sign)

Carrier

Shipping Boxes

Collector Containers

Shipping Bottles ( 8 oz.)

TCM Bottles ( 1 oz.)

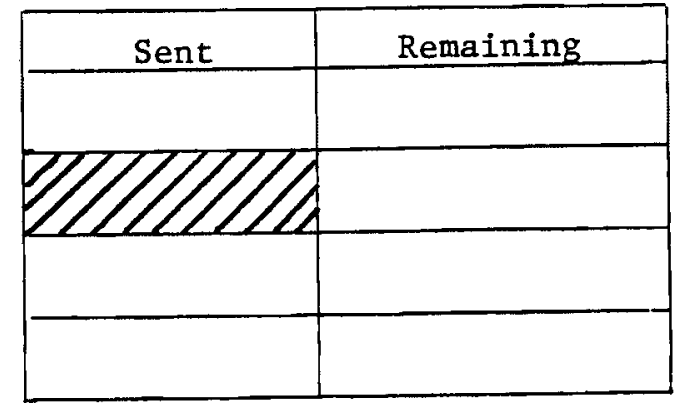

Site Needs:

Period Covered by Samples

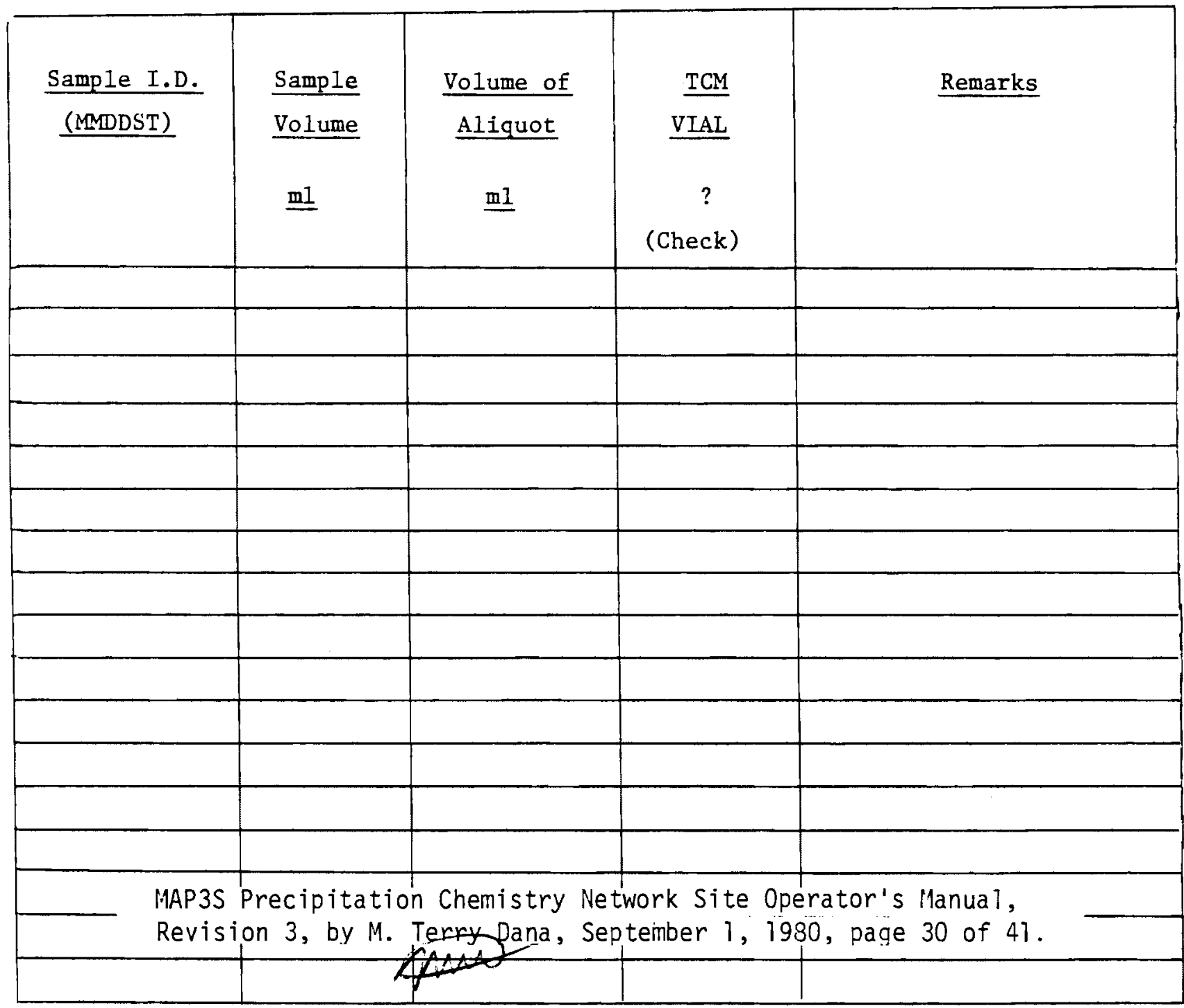

Form Date 10/15/76

by $\leq 4$
Revised $7 / 10 / 78$

by 20
Revised 10/25/79

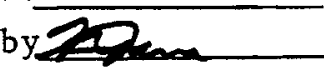


MAP3S PRECIPITATION CHEMISTRY NETHORK DATA LOG

Page of

Samples Aandled According To site Operacor's Manual Procedures

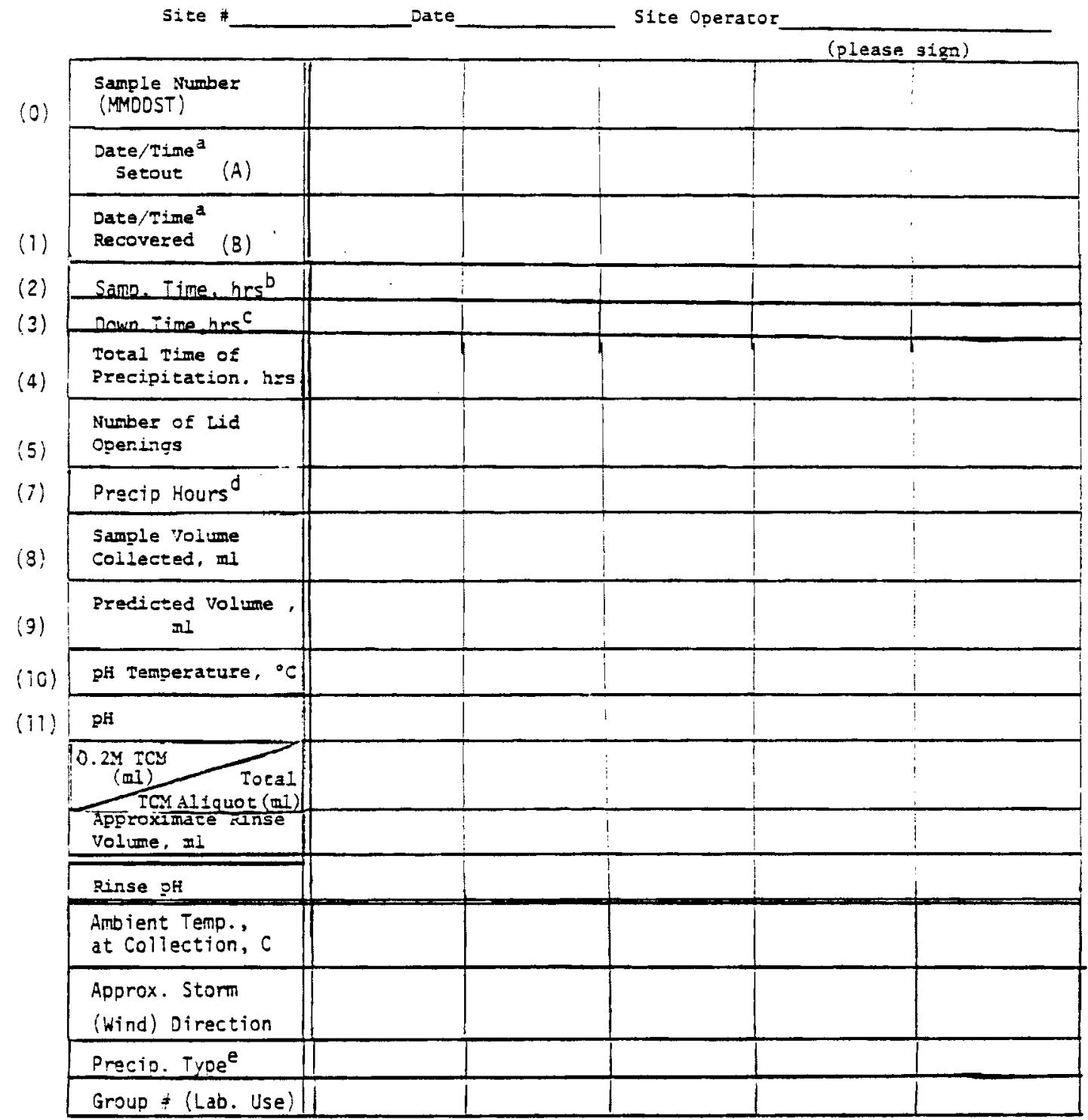

Remarks (Include down time, missed events (if any), possible contamination, unusual events, equipment needs):

a--Use GiMT and mark "Z".

$b--(B)-(A)$; Time collector is in olace

c--Difference in time between (A) of

this sample and (B) of previous sample.

$d$--Hours of day of precip (.NA if separate

precip. record is kept)

e--Use standard codes ( $R, R W, S, S W$, etc.--see operator's manual)
Codes: NA--not apolicable ISA--insuficicient sample volume VAP--no measurement LEAVE VO BLANK SPACES

Areas:ACM/HASL -640 Bivi- $-490 \mathrm{~cm}^{2}$

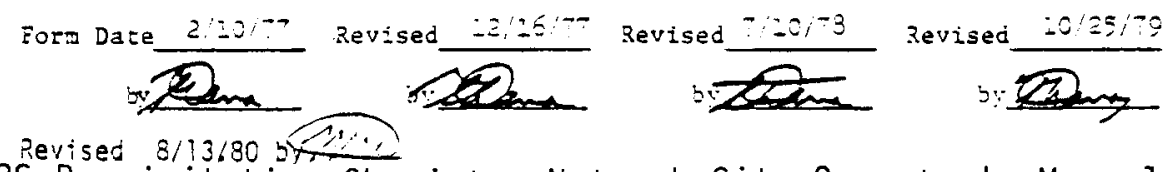

MAP3S Precipitation Chemistry Network Site Operator's Manual,

Revision 3, by M. Terry Dana, September 1, 1980, paqe 31 of 41 . 
Precipitation Time - If the total hours of precipitation listed do not match up with the period in the hours/dates row, please explain.

\section{D. SITE RECORDS}

Please retain raingauge and event recorder charts, and worksheets, if any, for sample collection, $\mathrm{pH}$ analysis, and shipping.

Do not send raingauge charts or copies if the Monthly Hourly Rainfall form is used (see Section 9). 


\section{SPECIAL SAMPLING PROCEDURES}

\section{A. WEEKLY SAMPLING}

During the period of weekly-event sample comparisons (certain sites only), collect samples according to the following protocol:

1. Collection time is Tuesday a.m. This should be adhered to as closely as possible. I need to compare similar time periods for the MAP3S sites, and future researchers will undoubtedly want to compare these data with the NADP data, also collected on Tuesday. Often collection cannot be made on Tuesday a.m. pressing commitments, holidays, etc. If you do collect other than Tuesday, please resume Tuesday collections as soon as possible thereafter.

2. Make collections for whole weeks. If there is a dry week (and you have reason to believe that the collector was not open appreciably during the week) leave it out until the next Tuesday. In fact, if you miss the Tuesday collection, it is better to have one two-week sample than one $1 / 2$ week and one $11 / 2$ weeks.

3. Make sure weekly precipitation hours agree with event precipitation hours. Even if you have a quality control (phony) sample during the week, add that fictitious time to the weekly precipitation time.

The purpose of the weekly sampling is to compare the results from weekly samples with those from the composite of the events during the week. Thus, the best weekly samples are those with discrete event samples within them. Feel free to delay pickup of the weekly sample (and its accompanying event sample) for up to 24 hours if precipitation is occurring Tuesday a.m. 


\section{B. RINSE SHIPMENTS}

Please do not normally ship BNW funnel rinse samples. Only do so if there is particular interest, e.g., high conductivity or abnormal $\mathrm{pH}$ of the rinse sample without obvious contamination. "High" conductivity would bez3umho/cm; abnormal pH might be $>6$ or $<4.5$.

MAP3S Precipitation Chemistry Network Site Operator's Manual Revision 3, by M. Jerry Dana, September 1, 1980, page 34 of 41 . ats 


\section{ROUTINE SAMPLE COLLECTION - ACM* COLLECTOR}

\section{A. PREPARATION FOR SAMPLE BUCKET CHANGE}

Take to the site a new bucket and lid, bagged separately. Always keep these items bagged until the moment of installation. Also required are wipes for cleaning the lid bottom pad. It is also desirable to take to the site the collector operating manual and tools for adjustment.

\section{B. REMOVING BUCKET}

Approach the collector from the downwind side, and deactivate automatic operation. (unplug or switch off). Expose the wet side bucket (be sure it is the wet side that you are changing!), and working from the downwind side, attach the new lid to the bucket with tape. This tape should be secure enough to prevent contamination on the way home. Mark date and time off on bucket along with ID.

\section{C. CLEANING LID BOTTOM PAD}

Take a clean wipe and run it around the lid bottom pad, over the area covering the bucket. Note any material which is not easily removed.

8.D. INSTALLING NEW BUCKET

Unbag the new bucket and place it in position on the wet side. Follow collector operator's manual procedure for securing the bucket. Close wet side, note seal, and adjust if necessary.

\section{E. RESTORE AUTOMATIC OPEPATION}

8.F. LOG DATA AS IN STEP 3.L. 


\section{G. LABORATORY HANDLING}

Note: These instructions are in addition to those appropriate from Section 4.

1. Remove tape and lid carefully. The large exposed area of the sample is especially prone to contamination, so perform the following steps (through sample division) with great care.

2. Weigh the bucket without lid. Note the tare weight and record the net.

3. If the sample is frozen replace lid and allow to thaw before proceeding.

4. Take pH aliqnot either by pouring (4.A. 2) or use the provided syringe, whichever is most convenient or less dangerous contamination-wise.

5. Remove TCM aliquot similarly. If the syringe is used to administer the TCM, be sure this is done well away from the sample and immediately discard the syringe.

6. Follow the rest of Sections $4-5$ as appropriate. 


\section{RAINFALL MEASUREMENT}

9.A. USE DAILY CLOCK (HOURLY RECORDING)

Follow raingauge manufacturer's instructions for operating in a daily recording mode. When mounting and unmounting charts or at any other time present at the site, place time marks on the chart. The clocks often do not keep good time, so time hacks are required to define hours. Be sure raingauge is level and free of debris in funnel.

9.B. RECORDING HOURLY RAINFALL ON PROVIDED FORM (PAGE 38)

Fill in all information at the top of the form. Use the back or a separate sheet for explanations of missing data, special circumstances, etc.

There is one row for each day of the month, and 24 columns for hours of the day. Each space on the form should be filled with the amount of rainfall in HUNDREDTHS OF INCHES (each tipping bucket tick is "0.01") for the hour ENDING AT THE TIME AT THE TOP OF THE COLUMN. Write the number as an integer (no decimal point) like this: 01 , $02, . .101, .$. .

The times are GMT as usual (EST +5, CST +6 ). Hour spaces with no precipitation, and the raingauge functional, SHOULD BE LEFT BLANK. Otherwise, fill in amount or symbol below:

ML Data record missing, with precipitation likely

MU Data record missing, with precipitation unlikely

$T$ Trace (if known for a fact by personal observation)

( ) Span of record where time resolution is greater than one hour. Enter amount for that period within parentheses. (Users of weekly charts will want to use these).

$\longleftrightarrow$ Indicates time span for symbcl.

Log precipitation form (snow, rain, etc.) on DATA LOG FORM.

MAP3S Precipitation Chemistry Network Site Operator's Manual, Revision 3, by M. Fexry Dana, September 1, 1980, page 37 of 41 . 


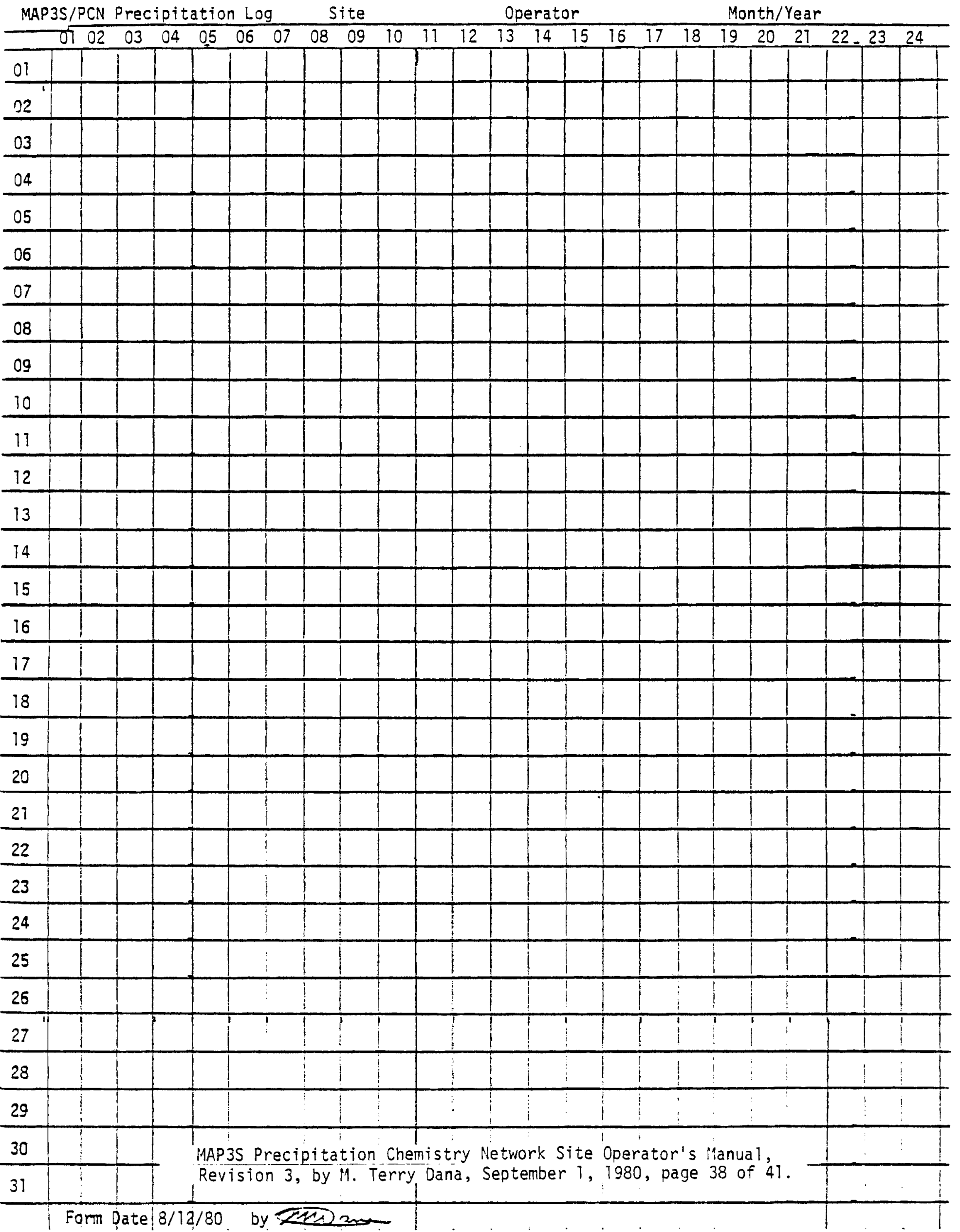


Mail the completed form at the end of each month. (Normally, with data log forms for the sample shipment which includes the last sample of the month).

\section{C. RAINGAUGE CALIBRATION}

The tipping bucket raingauge provided by Battelle should be calibrated periodically.

These raingauges are supposed to tip for every $0.01^{11}(0.0254 \mathrm{~cm})$ of precipitation. Since there are two sides, alternate tips will not necessarily represent the same amount of precipitation. This is especially true if the gauge or the pivot mount is not level - in this case, one side will tip too quick and the other too slow. Other problems may arise from dirt in the "cups" or a sticky or intermittent mercury switch.

The amount of water required to make one tip is, of course,

$$
V=.0254 \mathrm{~A}\left(\mathrm{~cm}^{2}\right) \quad\left(\mathrm{cm}^{3}\right)
$$

where $A$ is the area of the funnel mouth. The area is about $325 \mathrm{~cm}^{2}$ (8" diameter) giving $V=8.25 \mathrm{ml}$, but you should measure the area of your unit. Administer a measured amount of water with a large syringe or sprayer bottle (set coarse) and note the number of ticks. Starting the run immediately after a tip is desirable for accuracy. Do this with the unit set up as it is for measurement (you may wish to place the recorder next to the gauge), administering the water to the funnel uniformly (start with the funnel wet) over the funnel collection area. I would recommend running through at least 10 ticks for each run and vary the rate of application. There is, of course, a maximum rate (beyond which the tipper cannot respond fast enough). It may be of interest to determine what this maximum rate is. If there is any problem, you can then remove the cover and look for the problem. If there is any problem, let us know (see Introduction) and we will try to resolve it.

Please send the results of your calibration runs, in any case. 
APPENDIX C

LABORATORY QUALITY CONTROL PROCEDURES (SELECTED) 
.

. 
The IAP3S Precipitation Chemistry Network

Quality Assurance Procedure 5.1*: Page 1 of 20

Calibration Procedures for Analytical ilethods

Revision No. 1, Aprit 24 , $T 980$

Approved:

Merrybana

\section{1.a DIONEX ION CHROMATOGRAPH}

Calibration procedures are documented in "Dionex Ion Chromatographs Operation and Maintenance" manual, filed in analytical laboratory, room 121 .

5.1.b PERKIN-ELMER ATOMIC ABSORPTION SPECTROPHOTOMETER

Calibration procedures are documented in "Analytical Methods for Atomic Absorption Spectrophotometry," Perkin-Elmer, Norwalk CT, March 1971, filed in analytical laboratory, room 121 .

5.1.c pH METERS

Calibration procedures are documented in manufacturer's operation manuals, filed in ASD Instrument Manuals file, room 123.

\section{1.d CONDUCTIVITY METER}

Calibration procedures are documented in manufacturer's operation manual, filed in ASD Instrument Manuals file, room 123.

\section{1.e TECHNICON AUTOANALYZERS}

Procedures for currently used methods follow.

*Reference 5.1 .1 .1 of QAP ASD-14 
The MAP3S Precipitation Chemistry Network

Quality Assurance Procedure 5.2*: Page 1 of 1

Procedure for Preparation, Pre-Cleaning, and Shipping of Sampling Equipment

Revision No. 0, Apt 24,1980

Approved:

M. T. Dana

\section{2.a POLYETHYLENE BOTTLES}

To ensure consistently clean sample containers (shipping and collection bottles) in use on the Network, all sample-contact materials are prepared at the PNL Laboratory. Precleaning of new polyethylene bottles is done through the following procedure:

1. Single rinse with distilled water (conductivity $\sim 2.5 \mu \mathrm{mho} / \mathrm{cm}$ ).

2. Double rinse with distilled, deionized water (conductivity $<1 \mu \mathrm{mho} / \mathrm{cm}$ ).

3. Soak overnight in deionized water (bottle completely full and capped).

4. Check of soak water to ensure conductivity $<1 \mu \mathrm{mho} / \mathrm{cm}$.

5. Drying in filtered laminar-flow hood.

Shipping bottles (250 $\mathrm{ml}$ ) are bagged, and collector bottles (2 1) are capped and the tops individually bagged prior to shipment to the sites.

\section{2.b ACM COLLECTOR BUCKETS}

1. Double rinse with distilled, deionized (DD) water - at least 1 gallon total.

2. Clean inside and top lid with natural sponge twice, with DD rinse between. Sponge is kept in DD water when not in use; sponge bath changed every two buckets.

3. Final DD rinse with at least one gallon DD water.

4. Fill with at least 2 gallons DD water and let soak overnight.

5. Conductivity check (see 5.2.a.4).

6. Dry in laminar flow hood.

7. Buckets are individually bagged and stacked prior to boxing for shipping.

*Reference 5.1.1.1 of QAP ASD-14 
The MAP3S/RAINE Precipitation Chemistry Network Quality Assurance Procedure 5.3*: Page 1 of 2

Procedure for Cataloging, Identification and Storage of Samples

Revision No. 3 September 4, 1980

Approved

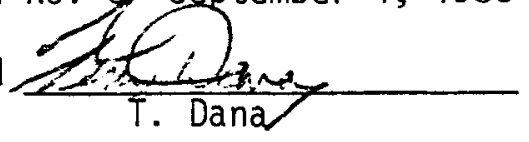

\section{3.a Sample Arrival}

1. Check receiving report for method of transport and source and discard.

2. Write on the box in pencil the site number and date of arrival.

3. Remove samples (check to make sure you have not left any hidden in the packing material), and count them.

4. Make an entry in the Site Batch Chronology form. Note:
a) Date of arrival.
b) Date of shipment (if Embarkation Form is available, in "Shipments Due" file).
c) Number of events (number of separate I.D. numbers ending in zero).
d) Total number of $8 \mathrm{oz}$. bottles.
e) First and last sample dates.

5. Compare Embarkation Form (if available) I.D.'s to received I.D.'s to assure arrival of all samples.

6. Enter samples in Analysis Checklist(s).
a) List in chronological order (this is important to avoid confusion later).
b) I.D. number is last 6 digits (omit year).
c) Fill in volumes for "PAR" and ANAL. aliquots. If no PAR, put a horizontal line in that space.
d) Put exactly 20 samples in each group, and start a new group in the middle of the shipment if necessary.

7. Put Group numbers on bottles and store.

a) Samples: If there are two bottles for a given I.D., write Group Number on one and store in refrigerator, and write Group Number and "PAR" on the other and store it in the refrigerator in the PAR compartment. (If the PAR bottle is completely full, pour off about $50 \mathrm{ml}$ before storing). If there is only one bottle for a given I.D., mark it with the Group Number and "A11," and store in refrigerator. The dishpans in the refrigerator each hold exactly one group (20 bottles). 
The MAP3S/RAINE Precipitation Chemistry Network

Quality Assurance Procedure 5.3: Page 2 of 2

Procedure for Cataloging, Identification and Storage of Samples

Revision No. 3 September 4, 1980

b) Vials: Write Group Number on the top and store in the refrigerator.

8. Write appropriate group numbers on Site Batch Chronology form.

\section{3.b Post-Analysis Storage}

1. When analysis of a group is complete (results checked and reported/placed in permanent data file), transfer sample bottles to freezer as follows:

a) Collect the bottles for a particular group.

b) For samples with a PAR, discard the non-PAR bottle.

c) Box the group and mark the contents clearly.

d) Indicate date of retirement on Analysis Checklist.

e) For empty samples (consumed by analyses), cross out the volume space or mark "MT".

f) File in freezer.

g) TCM vials are discarded after analysis. 
The MAP3S/RAINE Precipitation Chemistry Network

Quality Assurance Procedure 5.4*: Page 1 of 2

Procedure for Data Logging, Verification and Reporting

Revision 1 September 5,1980

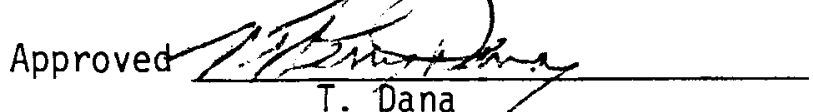

\section{4.a Data Logging}

1. File field forms.

a) Embarkation forms - in "Shipments Due" file until samples arrive, then in site folders in receiving desk.

b) Data Log Forms - in folders for sites on data logging table.

2. Open computer data file and log field data.

a) When samples are logged on Analysis Checklists and Data Log Forms have arrived, open files (in the appropriate group files) for the samples by remote terminal.

b) Enter data for the field data "species", numbers 1-11 (see left margin of Data Log Forms).

c) Place a red dot in space just to right of the sample I.D. spaces on Analysis Checklist, and write group number(s) in that space on the Data Log Form. When one Data Log Form page is complete, write date of logging in lower left hand corner.

3. Log Chemistry Data

a) When analyses are complete, $\log$ (by remote terminal) the remaining species $(12,14-20,22-27)$. (The computer calculates 13, 21, and 28).

b) Try to complete one group at a time.

c) When all species of a sample are entered, fill in red the space just to the right of the I.D. on the Analysis Checklist.

4. Verify data for groups.

a) When a group has been filled with data, dump the group and check all numbers with the original data.

b) Inspect ion balance for any questionable discrepancy (comparing with analyst calculated values), and order any necessary reruns.

${ }^{\star}$ Reference 5.1.1.1 of QAP ASD-14. 
The MAP3S/RAINE Precipitation Chemistry Network

Quality Assurance Procedure 5.4: Page 2 of 2

Procedure for Data Logging, Verification and Reporting

Revision 1 September 5, 1980

c) Make changes on file to correct errors.

5. ORDER groups.

a) Use ORDER command to place samples in chronological and site order.

b) Fill in red space (above first I.D.) on Analysis Checklist and mark with "EC \& O" and date.

6. Make Bimonthly Report.

a) When all groups of a bimonthly report are EC \& 0 , form a permanent file of the combined groups and request line printout. Enter first page data and comments.

b) Verify data on printout (check with original data).

c) Submit printout to USGS for quality control sample culls.

d) Remove culled samples from bimonthly report file and request another printout.

e) Reproduce and distribute report.

f) Erase non-permanent group files for those groups on bimonthly report. 
APPENDIX D

EXTERNAL LABORATORY QUALITY CONTROL:

SUBMISSION OF QUALITY ASSURANCE SAMPLES 


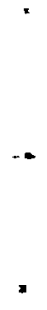




\title{
MAP3S PRECIPITATION CHEWISTRY NETWORK
}

\author{
Submission of Quality Assurance Samples
}

The U. S. Geological Survey has accepted responsibility for external quality assurance of the $1 M A P 3 S$ precipitation chemistry' network. This responsibility is limited to external quality control through the use of "blind" reference samples submitted to Battelle Pacific Northwest Laboratories. Onc major goal of this exicrnal QC program is to aid in the intercomparison of MAP3S and National Atmospheric Deposition Prozram (NADP) data. "Blind" reference samples are an attempt to limit possible laboratory and analyst bias.

Your willingness to participate in this external CC program is essential. The following guidelines and instructions were formulated attempting to keep your additional effort to a minimum. If you encounter any difficulties in the operational aspects of this externai QC program, please contact me (business card enclosed) and inform Terry Dana, Bat:elle Pacific Northivest Laboratories of the problem.

1) The sample you receive from the USGS will be in a $500 \mathrm{ml}$ polyethylene bottle with two pre-addiressed cards. General proposed submission dati is recorcied on the bottle.

2) Reference sample should be submitted to the laboratory during a period which your site has no wet deposition or when the sample will simulate an event sample. Do not send the reference sample in-place-of a deposition sample.

3) Treat the reference sample bottle as if it were a collected sample bottle or bucket. Proceed to measure pH, divide into shipping bottles and ship as normal samples.

4) Record pH value on both pre-addressed cards and Network data log (see fig. 5 of site operator's manual).

5) Information normally given on Network data log must be fill-in befcre suomission of $\log$ and reference sample to the laboratory. Where necessary, inclucie fictitious but crecible information.

6) Ship sample and data log in the same manner as the wet deposition sample to Batelle Laboratories.

7. Complete the iniormation requested on the two pre-addressed cards and mail them.

The data from the reference sample sent to the laboratory will be deleted from the normal data files betore the laboratory report is made to the frogram manager. Two cards are used to ensure that reference sample data does not become part of the llet deposition data files. Actual data removal will be handled by the laboratory and will not require any action by you. 


\section{COPY}

\section{NATIONAL ATMOSPHERIC DEPOSITION PROGRAM NC-141 \\ Submission of Quality Assurance Samples}

The U. S. Geological Survey has accepted responsibility for quality assurance of the Central Analytical Laboratory (CAL). One aspect of the program involves the submission of reference samples through the field collection sites in order to disguise the reference samples and limit analyst bias.

Thank you for your willingness to participate in this program. The following are instructions and guidelines for the program:

1) Reference samples should be submitted to the CAL during a week in which your site had no wet deposition.

2) The reference sample is to be shipped in a $500 \mathrm{ml}$ polyethylene bottle with two pre-addressed cards and a mailing label to send your dirty wet-side bucket to the USGS.

3) When you are ready to submit the reference sample, pour the contents of the bottle into a clean sample bucket. Weigh and record as usual.

4) Remove your normal aliquot and measure $\mathrm{pH}$ and conductance. Record these values as usual.

5) Transfer the data that came with the sample to your report form, and ship the report form with the sample to CAL (sampler depth and raingage amount).

6) Complete the information requested on the two post cards and mail them.

7) Remove'the dry wet-side bucket from the sampler and send it to USGS (using label provided). This bucket will be cleaned and returned to you for future use.

8) Place a clean bucket in the collector and proceed as usual. 


\section{DISTRIBUTION}

No. of

Copies

OFFSITE

A. A. Churm

DOE Chicago Patent Group

9800 S. Cass Avenue

Argonne, IL 60439

27 DOE Technical Information Center

Mr. Robert W. Beadle

Office of Health \&

Environmental Research

MS E-201, Germantown

U.S. Department of Energy

Washington, DC 20545

Van Bowersox

Illinois State Water Survey

Box 232

Urbana, IL 61801

Tom Butler

Ecology and Systematics

Cornel1 University

Langmuir Laboratory

Ithaca, NY 14853

Tom Church

Department of Marine Sciences

University of Delaware

Newark, DE 19711

Ellis B. Cowling

Prof. of Plant Path. \&

Forest Resources

North Carolina State University

P.0. Box 5397

Raleigh, NC 27607

Rosa dePena

Department of Meterology

Pennsylvania State University

University Park, PA 16802
No. of

Copies
Marc DuBois

Atmospheric Sciences Research Center Whiteface Mtn. Field Station Wilmington, NY 12997

Kurt Eastman

University of Delaware

Department of Marine Sciences

Lewes, DE 19958

Herbert W. Feely

EML

Department of Energy

376 Hudson Street

New York, NY 10014

Dr. James N. Galloway

Department of Environmental Sciences

University of Virginia

Charlottesville, VA 22903

James H. Gibson

Natural Res. Eco. Lab.

Colorado State University

Fort Collins, CO 80523

Bruce B. Hicks

Argonne National Laboratories

D-181

9700 South Cass Street

Argonne, IL 60439

John Jansen

Southern Company Services, Inc. Research Department, Room 812 P.0. Box 2625

Birmingham, AL 35202 
No. of

Copies

John Kadlecek

ASRC-SUNYA ES-324

1400 Washington Ave.

Albany, NY 12222

Bill Keene

Department of Environmental

Science

Clark Hall

University of Virginia

Charlottesville, VA 22903

Dr. John Klink

Department of Geography

Miami University

Oxford, $\mathrm{OH} 45056$

Bruce Komadino

Illino is State Water Survey

Water Resources Building

P.0. Box 232

Urbana, IL 61801

Gene Likens

Cornell University

Langmuir Laboratory

I thaca, NY 14853

Steve Lindberg

Environmental Sciences

Division

Oak Ridge National Laboratory

P.0. Box $X$

Oak Ridge, TN 37830

Michael C. MacCracken

University of California

Lawrence Livermore Laboratory

P.0. Box 808

Livermore, CA 94550

Dr. Paul Michae]

Meteorology Group

Brookhaven National Laboratories

Upton, L.I., NY 11973
No. of

Copies

Dr. John Miller

Air Resources Laboratory

NOAA, R32

8060 13th Street

Silver Spring, MD 20910

Robert Moore

Institute of Environmental Sciences

Boyd Hall

Miami University

Oxford, $\mathrm{OH} 45056$

Donald H. Pack

1826 Opalocka Drive

McLean, VA 22101

Dr. Gilbert S. Raynor

Atmospheric Sciences Division

Brookhaven National Laboratory

Associated Universities, Inc.

Upton, NY 11973

LeRoy Schroder

USGS

P.0. Box 25046

MS-407

Denver, C0 80225

John Takacs

Department of Meteorology

530 Walker Building

Pennsylvania State University

University Park, PA 16802

Leo Topol

Rockwell International

2421 W. Hillcrest Drive

Newbury Park, CA 91320

Dr. John Wyngaard

National Center for Atmospheric

Research

P.0. Box 3000

Boulder, CO 80302 
No. of

Copies

Dr. John Bachman

U.S. Environmental Protection Agency

MD- 12

Research Triangle Park, NC 27514

Dr. Leonard Barrie

Environment Canada

Atmospheric Environment

4905 Dufferin Street

Downsview, Ontario

M3H 5T4

Mr. Jack Durham

U.S. Environmental Protection Agency

Research Triangle Park, NC 27514

Dr. Glen Hilst

Electric Power Research Institute

$3412 \mathrm{Hillview} \mathrm{Avenue}$

P.0. Box 10412

Palo Alto, CA 94304

Dr. Rudy Husar

Washington University

St. Louis, MO 63130

Dr. Al Lazrus

National Center for Atmospheric Research

P.0. Box 3000

Boulder, CO 80302

Dr. Rick Linthurst

North Carolina State University

Box 5186

Raleigh, NC 27650

Dr. Richard G. Semonin

Illinois State Water Survey

P.0. Box 232

Urbana, IL 61801
No. of

Copies

Dr. Lennart Granat

Department of Meteorology

University of Stockholm

S-106 91 Stockholm

Sweden

Dr. Sjaak Slania

ECN

Netherlands Energy Research Foundation

Research Centre

3. Westerduinweg

Petten (NH)

Netherlands

Dr. Ray Wilhour

U.S. Environmental Protection Agency

2000 S.W. 35th Street

Corvalis, OR 97330

ONSITE

DOE Richland Operations Office

H. E. Ransom

41 Pacific Northwest Laboratory

M. T. Dana (25)

R. L. Drake

D. R. Drewes

C. E. Elderkin

R. C. Easter

F. O. Gladfelder

J. M. Hales

R. N. Lee

J. E. Rothert

B. C. Scott

Technical Information (5)

Publishing Coordination (2) 


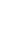

$\checkmark$

$\checkmark$ 